\title{
Induced pluripotent stem cells as a model for diabetes investigation
}

SUBJECT AREAS:

INDUCED PLURIPOTENT STEM CELLS

STEM-CELL DIFFERENTIATION

Received

20 August 2014

Accepted

27 January 2015

Published

26 February 2015

Correspondence and requests for materials should be addressed to J.D. (jozef.dulak@uj. edu.pl) or A.J. (alicja. jozkowicz@uj.edu.pl)

* These authors contributed equally to this work.

\author{
J. Stepniewski' , N. Kachamakova-Trojanowska' , D. Ogrocki' , M. Szopa ${ }^{2,3}$, M. Matlok' ${ }^{4}$, M. Beilharz', \\ G. Dyduch ${ }^{5}$, M. T. Malecki²,, A. Jozkowicz * \& J. Dulak ${ }^{1,6 *}$
}

'Department of Medical Biotechnology, Faculty of Biochemistry, Biophysics and Biotechnology, Jagiellonian University, Krakow, Poland, ${ }^{2}$ Clinic of Metabolic Diseases, Jagiellonian University Medical College, Krakow, Poland, ${ }^{3}$ University Hospital Krakow Poland, ${ }^{4}$ II Clinic of General Surgery, Collegium Medicum, Jagiellonian University, Krakow, Poland, ${ }^{5}$ Department of Clinical and Experimental Pathomorphology, Jagiellonian University Medical College, Krakow, Poland, ${ }^{6}$ Malopolska Centre of Biotechnology, Jagiellonian University, Poland.

Mouse and human induced pluripotent stem cells (iPSCs) may represent a novel approach for modeling diabetes. Taking this into consideration, the aim of this study was to generate and evaluate differentiation potential of iPSCs from lep $p^{d b / d b}(\mathrm{db} / \mathrm{db})$ mice, the model of diabetes type 2 as well as from patients with Maturity Onset Diabetes of the Young 3 (HNF1A MODY). Murine iPSC colonies from both wild type and $\mathrm{db} / \mathrm{db}$ mice were positive for markers of pluripotency: Oct $3 / 4 \mathrm{~A}$, Nanog, SSEA1, CDy1 and alkaline phosphatase and differentiated in vitro and in vivo into cells originating from three germ layers. However, our results suggest impaired differentiation of $\mathrm{db} / \mathrm{db}$ cells into endothelial progenitor-like cells expressing CD34 and Tie2 markers and their reduced angiogenic potential. Human control and HNF1A MODY reprogrammed cells also expressed pluripotency markers: OCT3/4A, SSEA4, TRA-1-60, TRA-1-81, formed embryoid bodies (EBs) and differentiated into cells of three germ layers. Additionally, insulin expressing cells were obtained from those partially reprogrammed cells with direct as well as EB-mediated differentiation method. Our findings indicate that disease-specific iPSCs may help to better understand the mechanisms responsible for defective insulin production or vascular dysfunction upon differentiation toward cell types affected by diabetes.

D iabetes mellitus is a group of complex metabolic diseases affecting more than 300 million people worldwide ${ }^{1}$. The most common form is type 2 diabetes (T2D) which is characterized by the lack of proper response to insulin in the peripheral tissues, a phenomenon known as the insulin resistance ${ }^{2}$. Additionally, T2D is accompanied by relative insulin deficiency resulting from defects in the secretion of this hormone ${ }^{3}$. Among others, this disease is also closely associated with cardiovascular complications, with endothelial cells being significantly affected ${ }^{4}$. Lep $p^{d b / d b}$ is a mouse strain frequently utilized as T2D model with the mutation in leptin receptor resulting in hyperphagy, obesity, hyperinsulinemia and hyperglycemia, the latter three reflecting clinical features of T2D patients ${ }^{5,6}$. Importantly, animal models based on disturbed leptin activity are often used to test new therapeutic approaches against $\mathrm{T} 2 \mathrm{D}^{7,8}$.

In contrast to $\mathrm{T} 2 \mathrm{D}$, monogenic forms of diabetes are rather rare, with the maturity onset of diabetes of the young (MODY) being the most frequent among them, constituting 1-2\% of diabetic cases ${ }^{9}$. HNF1A MODY (MODY3) is the most common form which results from the mutations in hepatocyte nuclear factor 1 alpha $(H N F 1 A)$ gene $^{10}$. This nuclear receptor is expressed in several organs, including pancreas, and controls the production of multiple factors responsible for glucose uptake, glycolysis and mitochondrial metabolism. Patients with MODY3 usually suffer from postprandial hyperglycemia and require pharmacological treatment with sulphonylureas or, in later stage, with insulin ${ }^{11}$. The molecular basis of this disease, similarly to T2D, has been characterized with the application of cell lines and animal models ${ }^{12}$, however utilization of patient-specific biological material could significantly enlarge our knowledge on the mechanisms of defective insulin production by the pancreatic $\beta$ cells.

Induced pluripotent stem cells (iPSCs) which resemble embryonic stem cells with their infinite self-renewal capacity as well as the ability to differentiate into all cell types constituting adult organism ${ }^{13,14}$, may provide the new possible source of such patient-specific material. Indeed, many groups demonstrated a feasibility of generating human iPSCs from patients suffering from different illnesses including metabolic disorders like type 1 and 2 of diabetes ${ }^{15,16}$ as wells as five forms of MODY $s^{17,18}$. Some of these studies described differentiation of hiPSCs towards insulin-producing cells ${ }^{18}$, however further optimization of this process seems to be necessary, especially 
for different types of MODYs. Additionally, iPSCs have been obtained from murine model of type 1 diabetes ${ }^{19}$ but not the others.

Here we report successful generation of induced pluripotent stem cells from the $L e p^{d b / d b}$ mice as the animal model of T2D as well as reprogrammed cells from patients diagnosed with HNF1A MODY. Additionally, this study demonstrates the feasibility of production of such cells to investigate the effects of diabetes on different cell types. Generated iPSCs can be further utilized to analyze the molecular mechanisms responsible for pathophysiology of diabetic disorders or be used for drug screening.

\section{Results}

Generation and characterization of mouse $\mathrm{db} / \mathrm{db}$ iPSCs. Transduction of tail tip fibroblasts isolated from control wild type (WT) and $L e p^{d b / d b}$ mice with STEMCCA lentiviral vectors resulted in generation of multiple colonies (within 2-3 weeks of reprogramming process) resembling mouse embryonic stem cells which could be further picked up and expanded (Figure 1A). No differences between cells from WT and $L e p^{d b / d b}$ mice were observed. This indicates that leptin signaling, which is disturbed in $\mathrm{db} / \mathrm{db}$ cells is not required for proper reprogramming outcome. Additionally, no changes in morphology of $\mathrm{db} / \mathrm{db}$ iPSCs were noticed in comparison to control counterparts as well as in the expression of pluripotency markers like Oct3/4A, Nanog and Sox2, both at mRNA and protein levels (Figure 1A-C). Expression of these transcription factors, which are the crucial components of self-renewal- and pluripotency-regulating signaling network, additionally indicated successful generation of induced pluripotent stem cells. Both WT and db/db iPSCs presented abundantly the SSEA1 carbohydrate epitopes, bound CDyl dye (Figure 1C), and expressed alkaline phosphatase (Figure 1D). On the other hand, Hmox1 (heme oxygenase-1), Prt4 (proteoglycan-4), and Agt (angiotensinogen) showed a tendency toward lower expressions in $\mathrm{db} / \mathrm{db}$ iPSCs than in WT cells (Figure 1E). This observation seems interesting, as proteoglycan-4 can promote development of hemangioblasts $^{20}$ and similar role has been ascribed to the angiotensin converting enzyme ${ }^{21}$, whereas heme oxygenase- 1 is a proangiogenic enzyme necessary for proper function of endothelial progenitors $^{22}$.

To further verify the pluripotency of iPSCs, they were subjected to spontaneous differentiation process through the formation of embryoid bodies (Figure 2). Indeed, after removal of feeder layer and LIF (leukemia inhibitory factor) stimulation, control and $\mathrm{db} /$ $\mathrm{db}$ iPSCs generated EBs which adhered to gelatin-coated wells (Figure 2A,B). Importantly, immunofluorescence analysis confirmed the expression of markers of different germ layers in the control and $\mathrm{db} / \mathrm{db}$ cells that further outgrew from the adhered EBs (Figure 2C,D). Finally, subcutaneous injection of either control or $\mathrm{db} / \mathrm{db}$ iPSCs into immunocompromised mice resulted in formation of teratomas which were composed of tissues characteristic for endoderm, mesoderm and ectoderm (Figure 2E,F). This experiment proved that both WT iPSCs and those generated from $L e p^{d b / d b}$ animals were pluripotent. Additionally, this demonstrated that functional leptin receptor is not crucial for the maintenance of pluripotency in iPSCs.

Endothelial differentiation of control and $d b / d b$ iPSCs. To stimulate endothelial differentiation, control and $\mathrm{db} / \mathrm{db}$ iPSCs were seeded on collagen IV to induce differentiation into mesoderm lineages and subsequently cultured on fibronectin in the presence of vascular endothelial growth factor (VEGF) to direct the process toward endothelial cells ${ }^{23}$. Of note, the fraction of $\mathrm{CD} 34^{+} \mathrm{Tie}-2^{+}$ subpopulation was much lower within differentiating $\mathrm{db} / \mathrm{db}$ cells than in control counterparts $(14.3 \%$ versus $88.4 \%$ at day 60 of differentiation, Figure $3 \mathrm{~A}$ ), suggesting that functional leptin signaling might influence this process. Nevertheless, either control or $\mathrm{db} / \mathrm{db}$ cells acquired characteristic endothelial-like cobblestone morphology (Figure 3B), and expressed endothelial markers, such as von Willebrand Factor (vWF), phosphorylated endothelial nitric oxide synthase (eNOS), and vascular endothelial growth factor receptor 1 (Flt-1) (Figure 3C). Phosphorylation of eNOS protein indicated its enzymatic activity. Indeed, the iPSC-derived endothelial progenitor-like cells produced nitric oxide (NO), with the same efficacy for both genotypes (Figure 3D).

Then, we compared the angiogenic potential of the iPSC-derived cells using a capillary sprouting assay (Figure 3E). Cells were suspended in medium containing methyl cellulose and seeded in Ushaped 96-well plate to form spheroids, which were subsequently embedded in collagen and stimulated with VEGF to produce capillary-like sprouts. The number and length of sprouts were analyzed after $48 \mathrm{~h}$, but in WT spheroids the outgrowth of sprouts was visible already after $24 \mathrm{~h}$. In contrast, db/db spheroids formed almost no capillary-like structures (Figure 3E,F). Namely, we demonstrated a significant impairment both in number and length of capillary like structures (Figure 3F). This observation suggests that cells obtained after endothelial differentiation of $\mathrm{db} / \mathrm{db}$ iPSCs display impaired angiogenic potential, the feature typical for endothelial cells isolated from $\mathrm{db} / \mathrm{db}$ mice. Indeed, we found a very similar impairment when spheroids were formed by $\mathrm{CD} 34^{+}$primary endothelial cells isolated from the lungs of wild type or $\mathrm{db} / \mathrm{db}$ mice (Figure $3 \mathrm{G}$ ).

Generation and characterization of HNF1A MODY reprogrammed cells. Similarly to mouse tail tip fibroblasts, human primary skin fibroblasts isolated from non-diabetic controls and HNF1A MODY patients were successfully reprogrammed using STEMCCA vectors. Multiple colonies were obtained 3 to 4 weeks after lentiviral transduction (Figure 4A). Since initially we encountered very low efficiency of successful expansion of reprogrammed after picking up and passaging single colonies, a different procedure was tested, where the generated colonies were detached together with nonreprogrammed fibroblasts and seeded onto gelatin-coated wells. After $0.5 \mathrm{~h}$ most of the fibroblasts, in contrast to reprogrammed cells, had already attached to the bottom of the well, which enabled a significant enrichment of the floating cell population with reprogrammed cells. Non-adhered cells were collected, seeded on Matrigel and further cultured. This step was helpful in successful expansion of human reprogrammed cells in our hands.

Further characterization of the obtained control and HNF1A MODY reprogrammed cells confirmed silencing of lentiviral reprogramming construct in two of four lines (Ctr Repro 2 and HNF1A MODY Repro 1, Figure 4B). Both control and HNF1A MODY cells expressed pluripotency markers, as shown using immunofluorescence analysis of OCT3/4A, SSEA4, TRA-1-60, and TRA-1-81 (Figure 4C,D). Concomitantly, they formed embryoid bodies after removal of bFGF stimulation and seeding on non-adherent dishes (Figure 5A). When EBs were transferred to the adherent, Matrigelcoated wells, the outgrowth of differentiating cells could be detected in the following days (Figure 5A). These cells expressed markers characteristic for all three germ layers, confirming the broad differentiation potential of generated human reprogrammed cells (Figure $5 \mathrm{~A}, \mathrm{~B}$ ). Nevertheless, despite multiple cell injections into immunocompromised mice, no teratoma generation was observed. In case of Ctr Repro 2, one of the injections resulted in development of malignant epithelial tumor (Figure $5 \mathrm{C}$ ).

Differentiation of control and HNF1A MODY reprogrammed cells toward a pancreatic lineage. To assess the potential of HNF1A MODY reprogrammed cells to differentiate toward insulinproducing cells, two methods have been tested, namely direct and embryoid bodies-mediated differentiation. The efficacies of these approaches were evaluated by analysing the expression of specific markers at mRNA levels. RT-PCR assay was employed to demonstrate expression of i) SOX17 and FOXA2, markers of definitive endoderm (DE, day 1-3), ii) $H N F 4 \alpha$, marker of gut endoderm (GTE, d3-9), and iii) HNF6, PDX1, HB9, NKX6.1 and 
A.
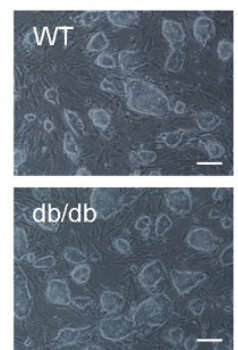

B.
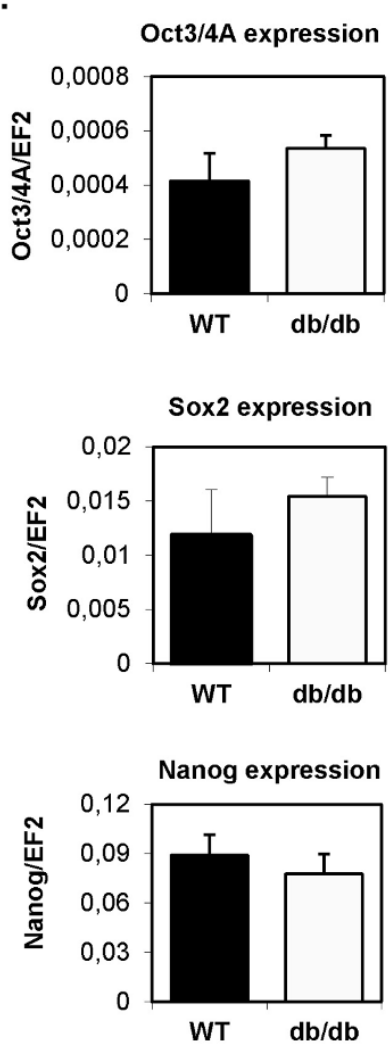

D.

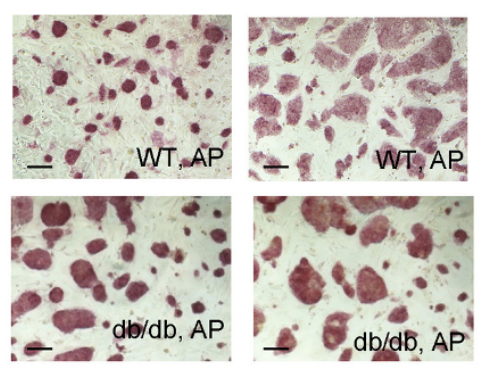

C.
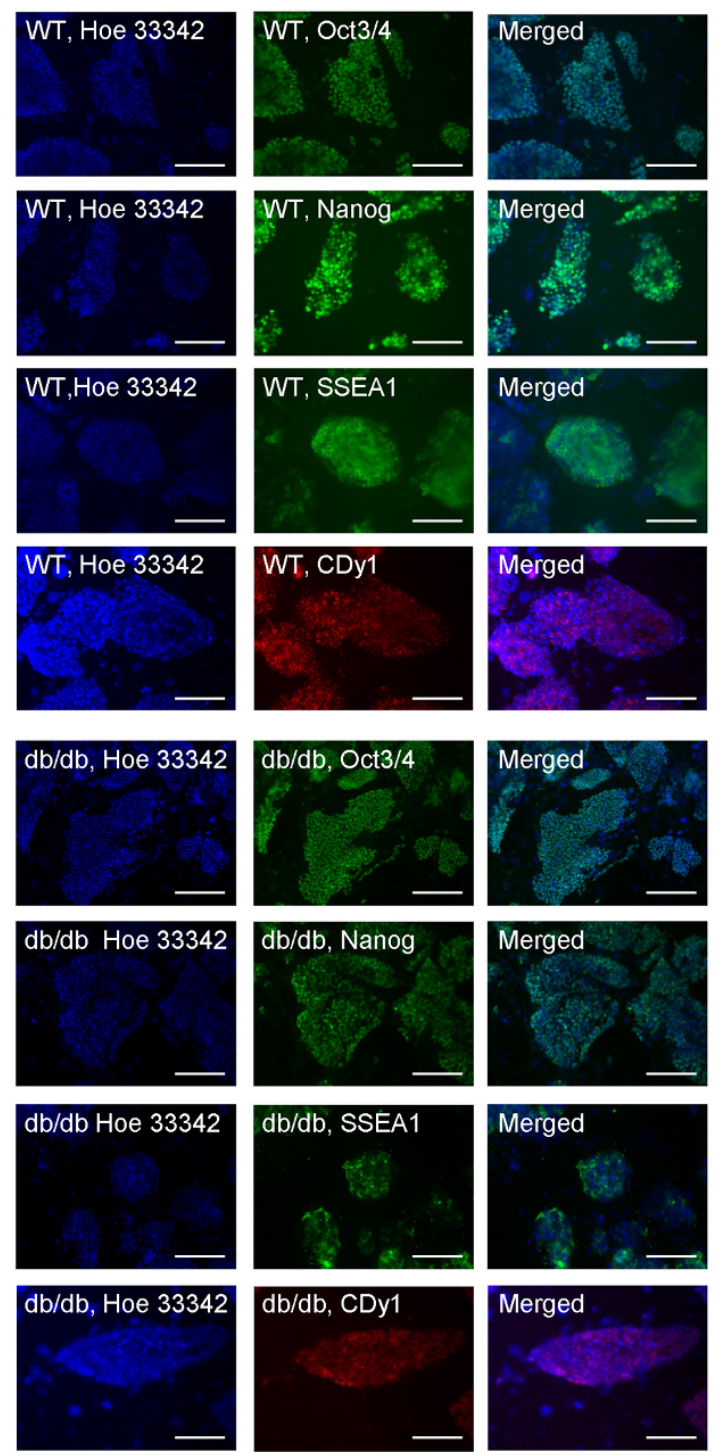

E.
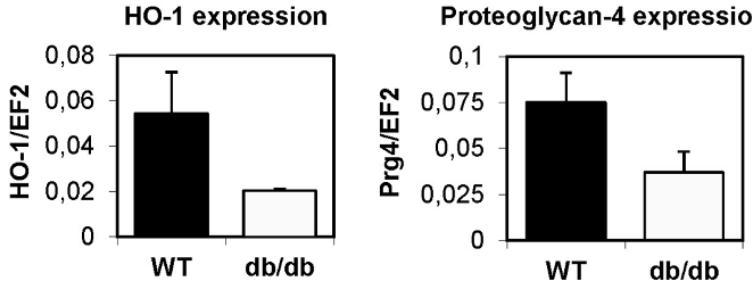

Angiotensinogen expression

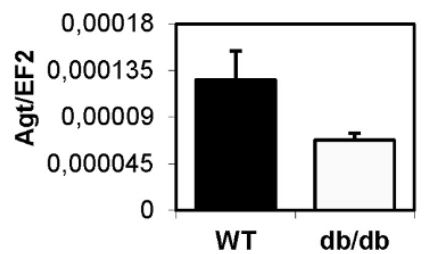

Figure 1 Generation of wild type (WT) and $L e p^{d b / d b}(\mathrm{db} / \mathrm{db})$ iPS cells. (A). Morphology of WT and db/db iPS cells. Representative pictures (scale bar $100 \mu \mathrm{m})$. (B). Expression of pluripotency markers: Oct3/4A, Nanog and Sox 2 in control and db/db iPSCs. Quantitative RT-PCR analysis. N = 3. (C). Immunofluorescence staining of pluripotency markers: Oct3/4A, Nanog, SSEA1 and CDy1 in WT and db/db iPS cells (scale bar - $100 \mu \mathrm{m}$ ). (D). Expression of alkaline phosphatase in WT and db/db iPS cells. Representative pictures (scale bar $-100 \mu \mathrm{m}$ ). (E). Expression of genes associated with endothelial lineage development: HO-1, proteoglycan-4 and angiotensinogen. Quantitative RT-PCR analysis. N = 2. EF2 gene was used as housekeeping gene. Each bar represents mean + SEM. The numerical data presented in Fig. 1B and 1E were not statistically significant. 
A.

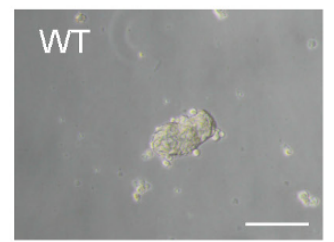

C.
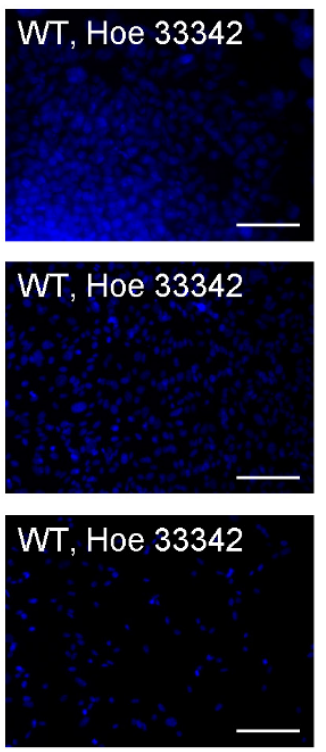

D.
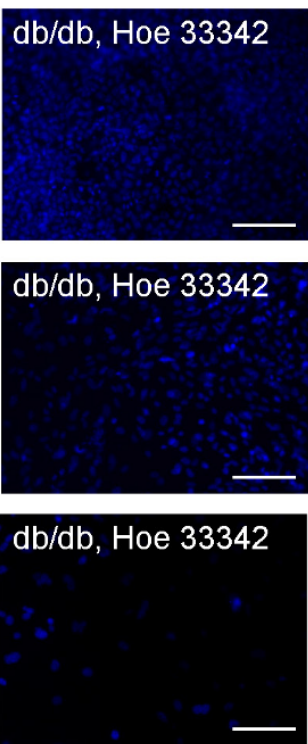

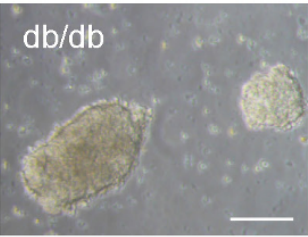

B.
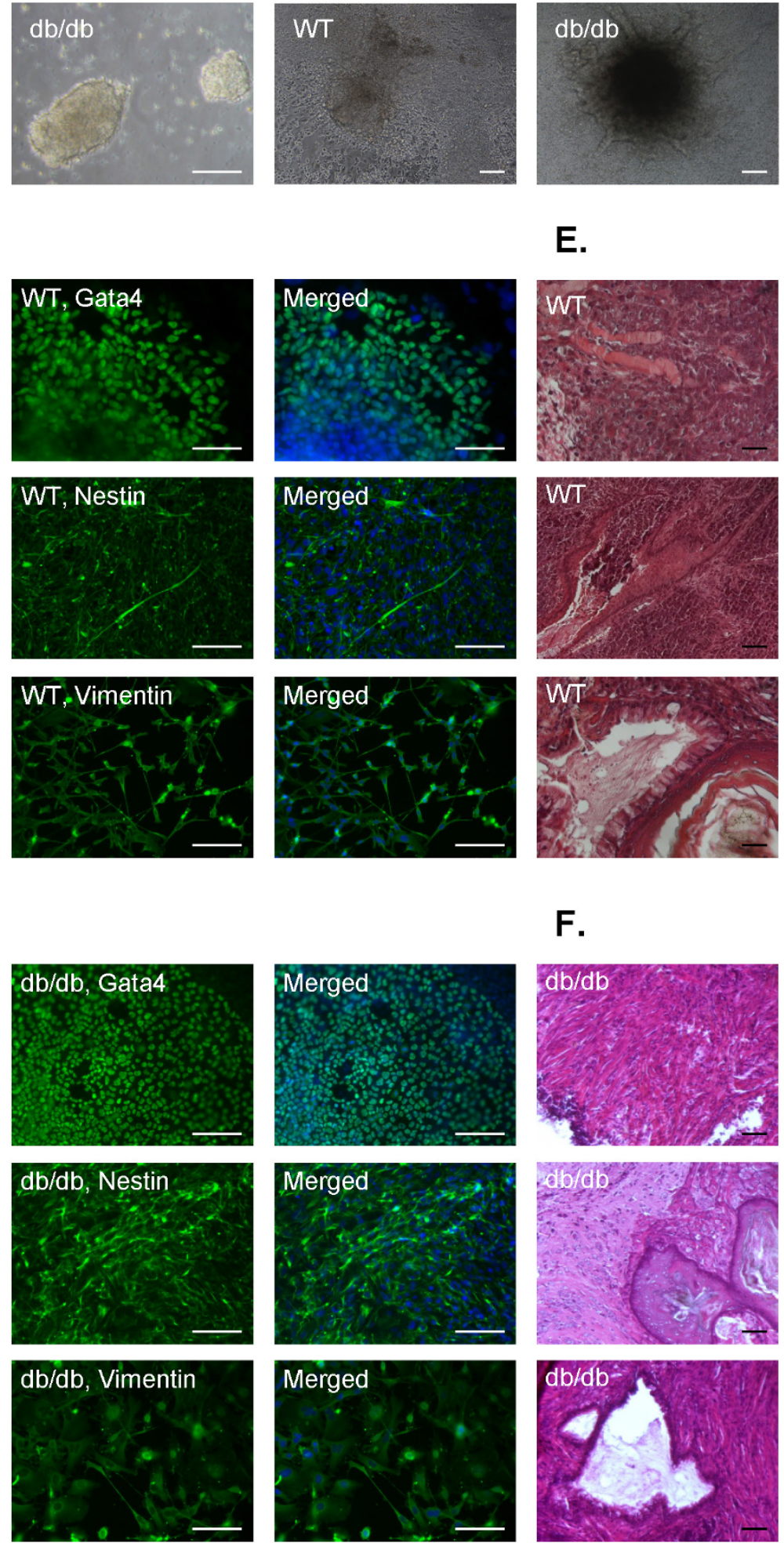

E.

F.
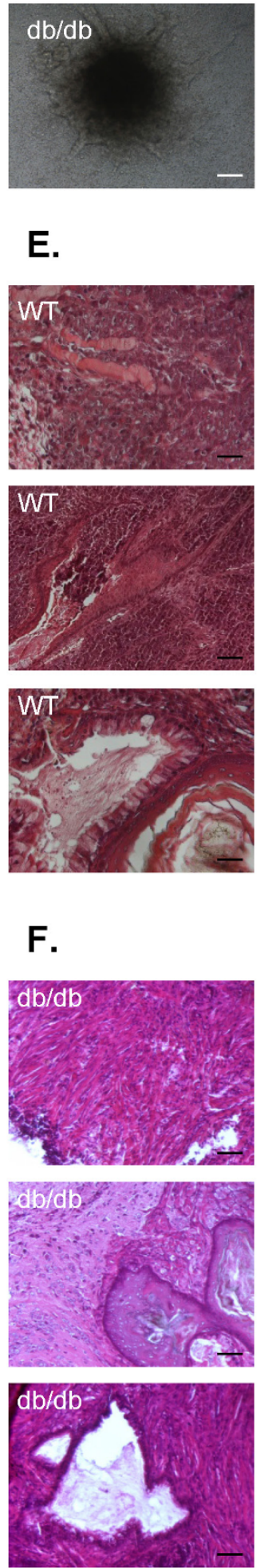

Figure $2 \mid$ Differentiation potential of wild type (WT) and $\operatorname{Lep}^{d b / d b}(\mathrm{db} / \mathrm{db})$ iPS cells. (A). Embryoid bodies formed from iPS cells after seeding on nonadherent dishes without LIF stimulation (scale bar $-100 \mu \mathrm{m}$ ). (B). Outgrowth of cells from embryoid bodies after adherence to gelatin-coated dishes. Outgrowing cells were further differentiating (scale bar $-100 \mu \mathrm{m}$ ). (C,D). Immunofluorescence staining of markers characteristic for three different germ layers after two weeks of spontaneous differentiation via embryoid bodies of WT iPS cells (C) or db/db iPS cells (D). Gata4 - marker of early and defined endoderm as well as mesoderm; nestin - marker of ectoderm; vimentin - marker of mesoderm. Representative pictures (scale bar - $100 \mu \mathrm{m})$. (E,F). Teratoma formation assay - representative pictures demonstrating tissues originating from three germ layers within a tumor developed after subcutaneous injection of WT iPS cells $(\mathrm{E}, \mathrm{N}=3)$ or $\mathrm{db} / \mathrm{db}$ iPS cells $(\mathrm{F}, \mathrm{N}=4)$ into immunocompromised mice. Upper - muscles (mesodrem), middle epidermis (ectoderm), bottom - ciliated epithelium (endoderm) (scale bar - $100 \mu \mathrm{m})$. 
A.
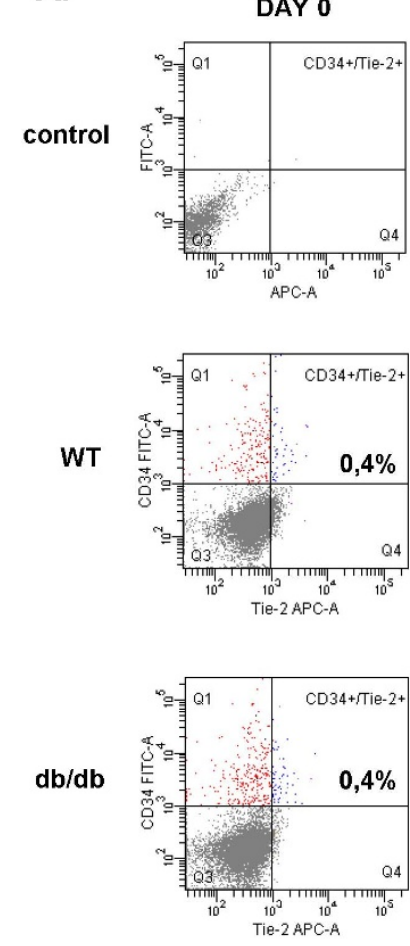

D.

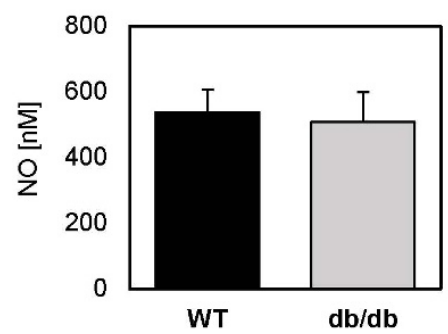

E.

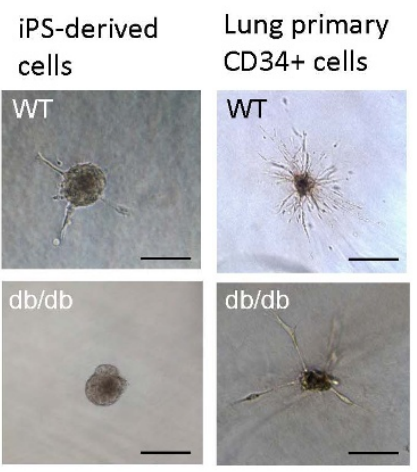

DAY 60
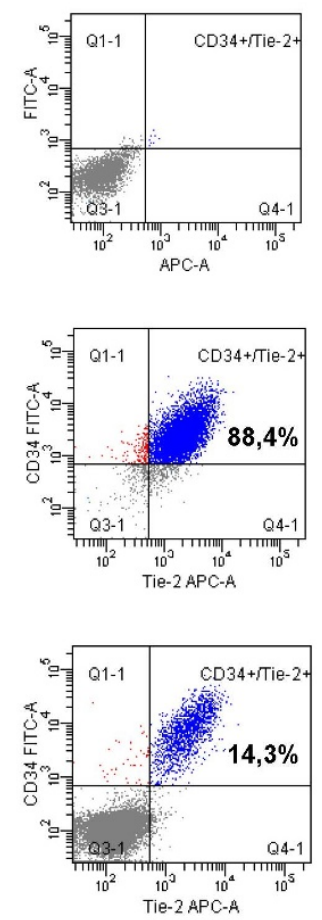

F.

Average number of sprouts

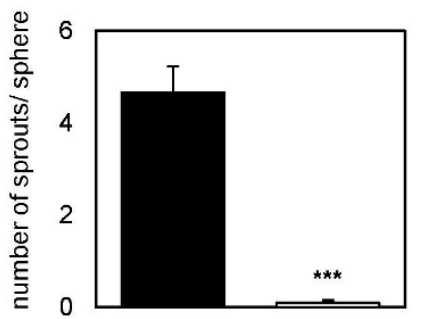

WT

$\mathrm{db} / \mathrm{db}$

Total sprout length

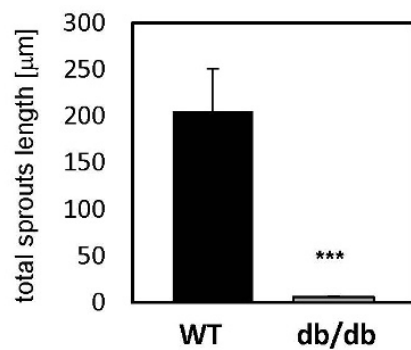

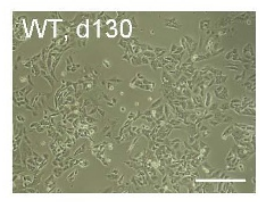

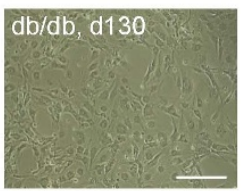

C.
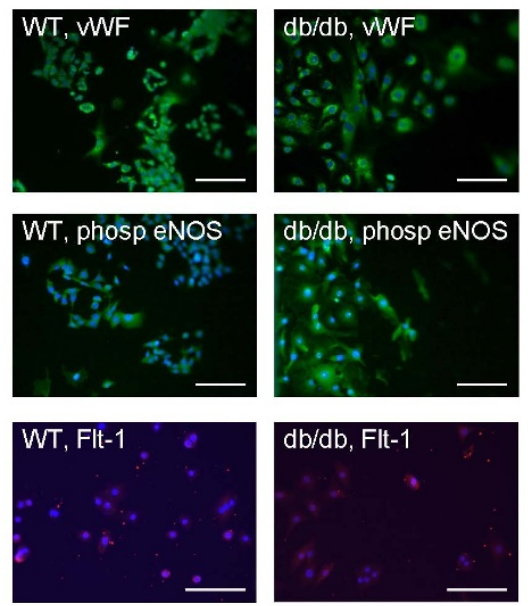

G.

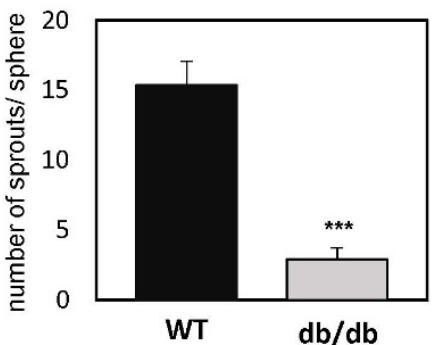

Total sprout length

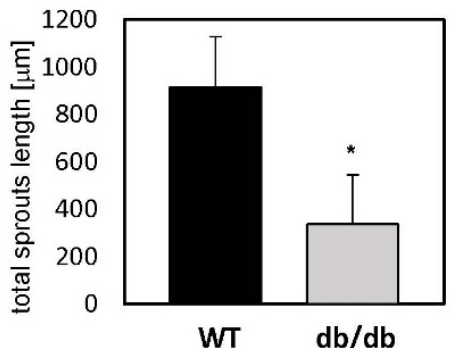

Figure $3 \mid$ Differentiation of wild type (WT) and $L e p^{d b / d b}(\mathrm{db} / \mathrm{db})$ iPS cells into endothelial progenitor-like cells. (A). FACS analysis of CD34 ${ }^{+}$Tie- $2^{+}$ population in WT and db/db iPSC-derived cells before differentiation (day 0) and after establishing the differentiated cell lines (day 60). Representative dot-plots. Control - unstained cells. (B). Morphology of WT and db/db iPSC-derived endothelial progenitor-like cell lines at $130^{\text {th }}$ day of culture.

Representative pictures. (C). Immunofluorescence staining of von Willebrand Factor (vWF), phosphorylated endothelial nitric oxide synthase (phosp eNOS), and vascular endothelial growth factor receptor 1 (Flt-1) in WT and db/db iPSC-derived endothelial progenitor-like cells (scale bar - $100 \mu \mathrm{m}$ ). (D). Nitric oxide production by WT and db/db iPSC-derived endothelial progenitor-like cells. Gas-phase chemiluminescence reaction $(\mathrm{n}=3$ ). (E). Sprouting spheres embedded in collagen, generated from WT and db/db iPSC-derived endothelial progenitor-like cells or lung primary CD34 ${ }^{+}$ endothelial cells isolated from WT and db/db mice. Representative pictures (scale bar $-100 \mu \mathrm{m})$. (F,G). Average number of sprouts and total length of sprouts measured for sprouting spheres embedded in collagen, generated from WT $\left(\mathrm{n}=12\right.$ spheres) and $L e p^{d b / d b}(\mathrm{n}=10$ spheres) iPSC-derived endothelial progenitor-like cells $(\mathrm{F})$ or lung primary $\mathrm{CD} 34^{+}$endothelial cells isolated from WT $(\mathrm{N}=5)$ and db/db $(\mathrm{N}=4) \mathrm{mice}(\mathrm{G})$. Each bar represents mean + SEM. $* p<0.05, * * * p<0.001$. 
A.
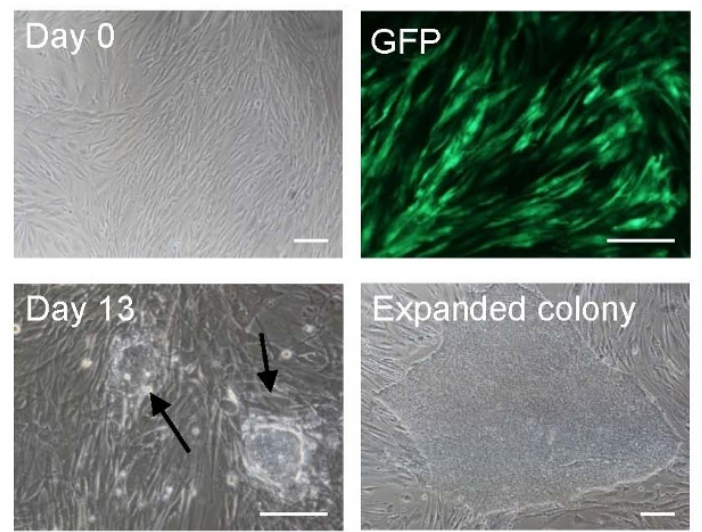

C.
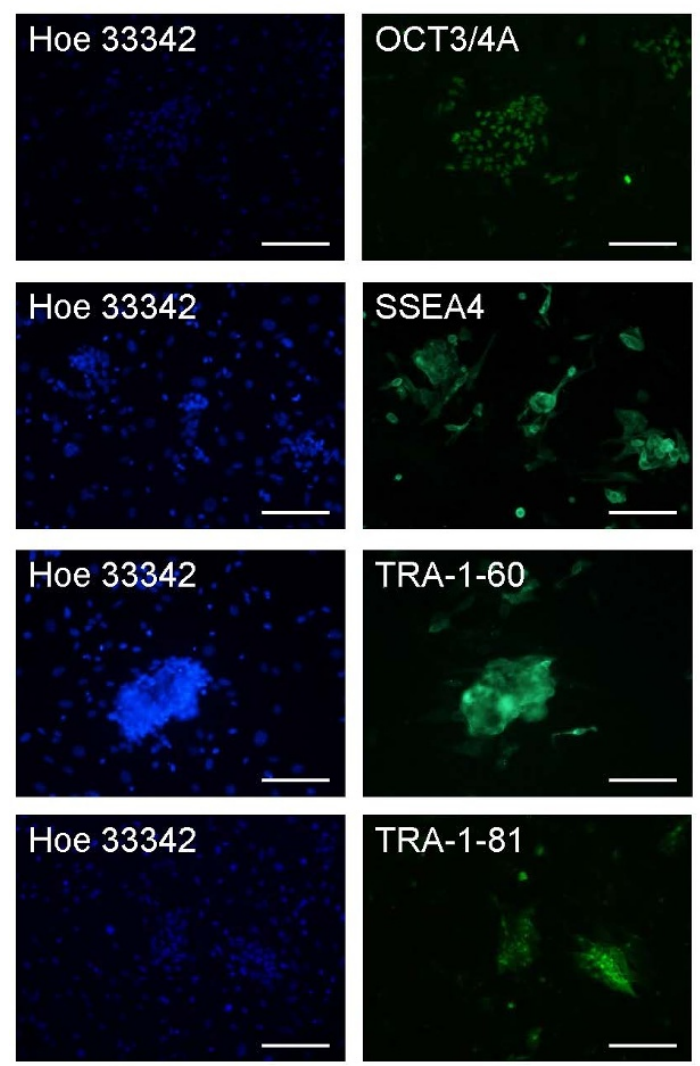

B.

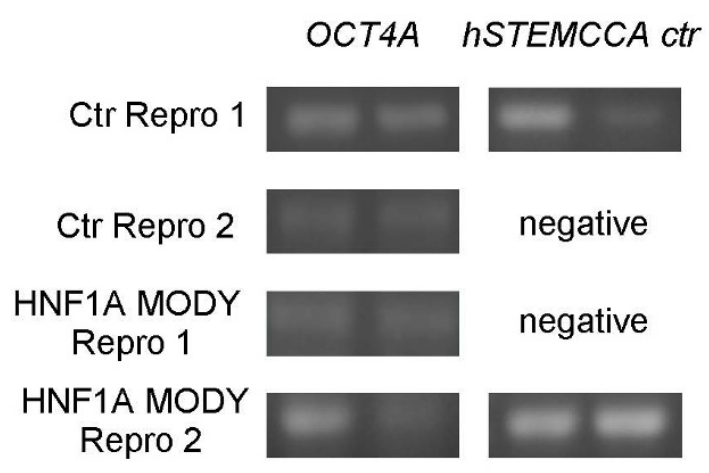

D.
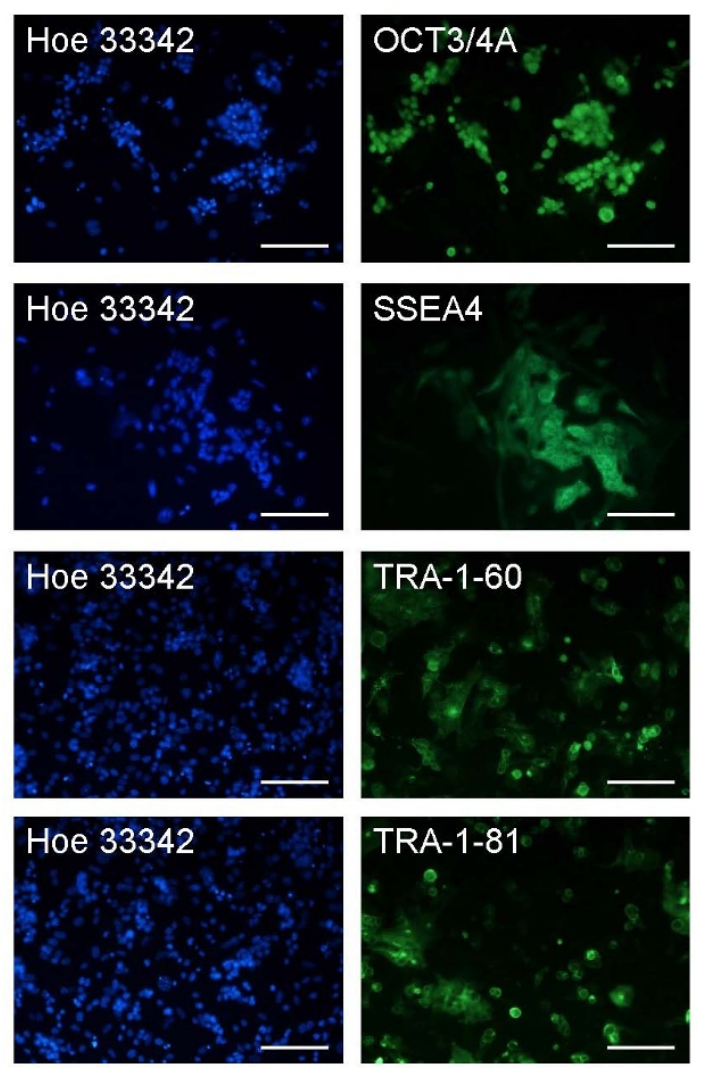

Figure $4 \mid$ Generation of human reprogrammed cells from fibroblasts of control healthy subjects and HNF1A MODY patients. (A). Morphology of cells from healthy subject before (day 0 ) and 13 days after transduction (day 13) with hSTEMCCA lentiviral vectors. Colonies resembling human embryonic stem cells, visible at day 13, were further expanded (expanded colony, shown at passage 2). GFP - expression of GFP in human primary fibroblast isolated from HNF1A MODY patients, 72 after transduction with control (FUGW) lentiviral vectors. Representative pictures (scale bar - $100 \mu \mathrm{m}$ ). (B). Analysis of hSTEMCCA construct silencing in established control (effective silencing in Ctr Repro 2 cell line) and HNF1A MODY reprogrammed cells (effective silencing in HNF1A MODY Repro 1 cell line). RT-PCR. (C,D). Immunofluorescence staining of pluripotency markers: OCT3/4A, SSEA4, TRA-160, TRA-1-81 in control reprogrammed cells (C) and HNF1A MODY reprogrammed cells (D). Representative pictures (scale bar - $100 \mu \mathrm{m})$.

NKX2.2, markers of pancreatic progenitor cells (PP, d9-19). The five latter mentioned markers were analyzed along with expression of insulin (INS) in the last step of development toward $\beta$-like cells (d19-25). A scheme describing the stages and time points of differentiation as well as photos of differentiating cells are shown in Figure $6 \mathrm{~A} \& \mathrm{~B}$. For the EB-based approach only three time points were tested, namely day $19^{\text {th }}, 24^{\text {th }}$ and $30^{\text {th }}$ (day $5^{\text {th }}, 10^{\text {th }}$ and $16^{\text {th }}$ upon seeding of cells on collagen I-coated plates (Figure 6C). To monitor the progression, the same markers as in the direct differentiation were analysed (SOX17, FOXA2, HNF4 $\alpha$ at day $19^{\text {th }}$; HNF6, PDX1, HB9 and NKX6.1 at day $24^{\text {th }}$; NKX2.2 and insulin after 30 days of differentiation). Morphology of differentiating cells in EB-based method is shown in Figure 6D.

In case of the direct approach, all specific markers were detectable in differentiating cell lines either derived from control or HNF1A MODY patients (Figure 7A). Similarly, in the method based on EB- 

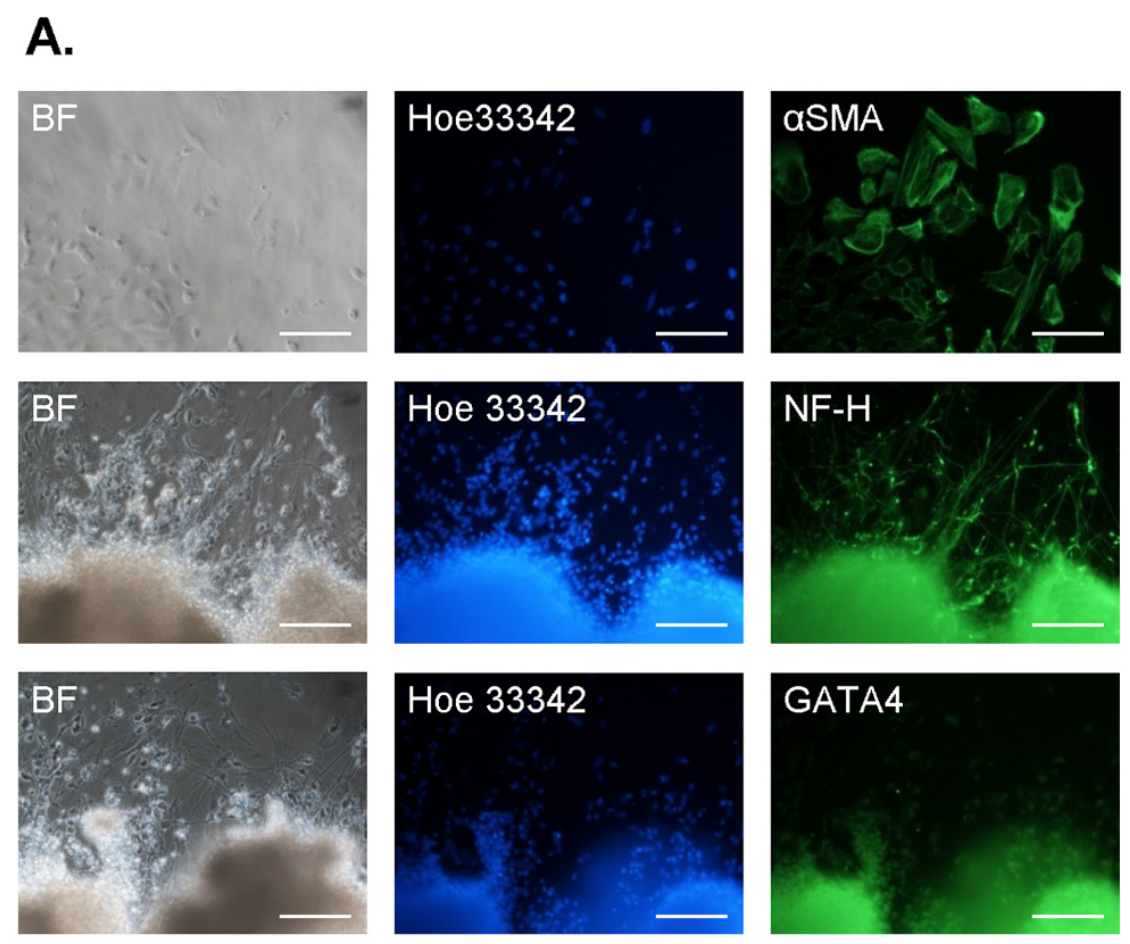

B.
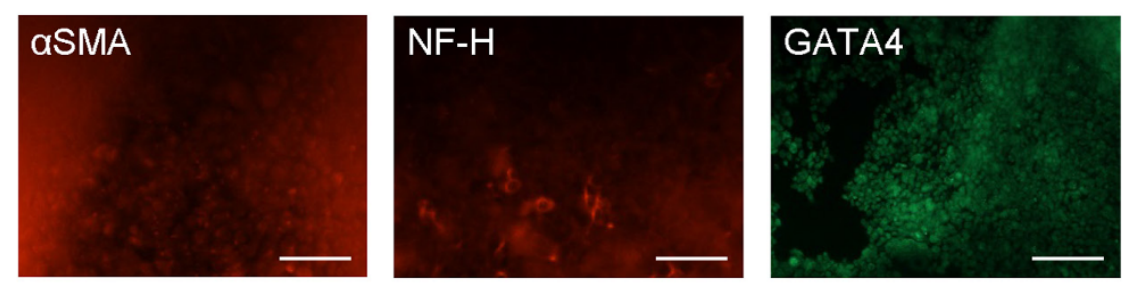

\section{C.}
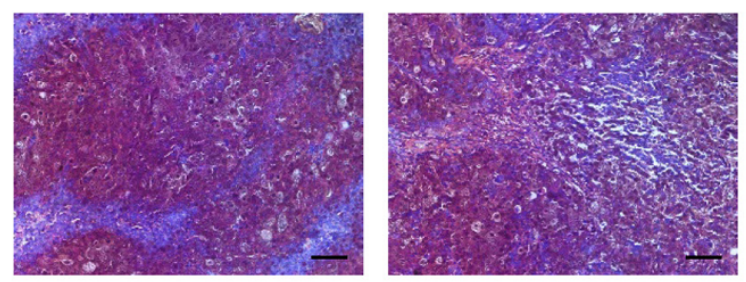

Figure $5 \mid$ Differentiation potential of human control and HNF1A MODY reprogrammed cells. (A,B). Immunofluorescence staining of markers characteristic for three different germ layers after two weeks of spontaneous differentiation via embryoid bodies. A - differentiating control reprogrammed cells. B - differentiating HNF1A MODY reprogrammed cells. GATA4 - marker of early and defined endoderm as well as mesoderm; neurofilament heavy chain (NF-H) - marker of ectoderm; $\alpha$ smooth muscle actin $(\alpha$ SMA) - marker of mesoderm (scale bar - $100 \mu \mathrm{m})$. (C). Histological staining of epithelial tumor formed in immunocompromised mouse after injection of human control reprogrammed cells. Representative pictures (scale bar $-100 \mu \mathrm{m})$.

mediated differentiation all markers, except FOXA2, were detectable in control and HNF1A MODY cells (Figure 7B). It must be stressed, however, that not all RT-PCR analyses produced the positive signals (Fig. 7C). This might result from a low efficiency of differentiation or not optimal time-point chosen for particular cell line. Importantly, markers of pancreatic progenitor cells (HB9, PDX1, NKX2.2, and NKX6.1) were detectable in each reaction performed (Fig. 7C). Nevertheless, in all cell lines studied the insulin was expressed at a very low level, what precluded performing reliable quantitative measurements (Fig. 7A-C). Accordingly, we could not reliably detect Cpeptide in media collected from differentiated cells, however we were able to measure the concentration of released glucagon (Fig. 7). The presence of glucagon indicates that utilized protocols enabled generation of immature, polyhormonal pancreatic cells, which is a usual outcome of in vitro differentiation methods ${ }^{24}$.

\section{Discussion}

We report in this study the successful generation of murine iPSCs from wild type and diabetic $\mathrm{db} / \mathrm{db}$ animals, as well as reprogrammed human cells from control individuals and diabetic HNF1A MODY patients. Both mouse iPSCs and human cells expressed pluripotency markers like Oct3/4A or Nanog and they were able to differentiate in 
A.

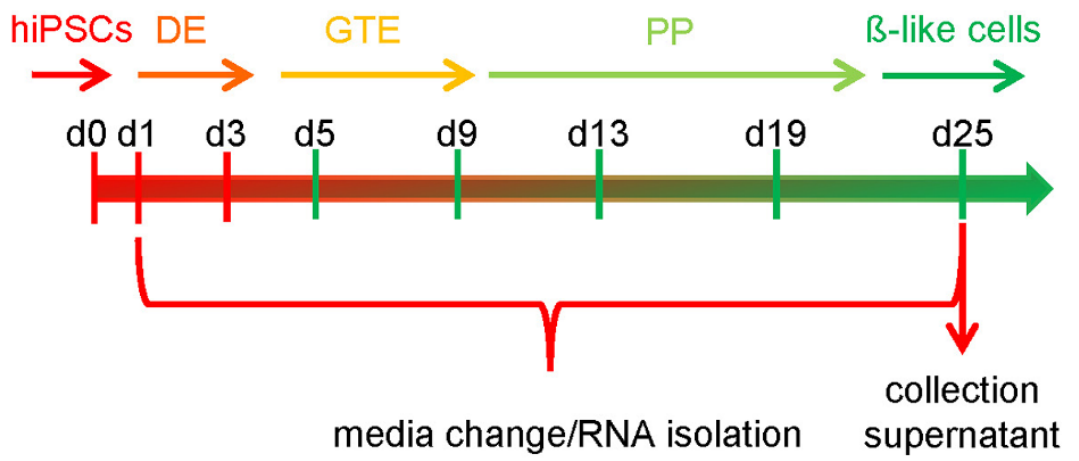

B.
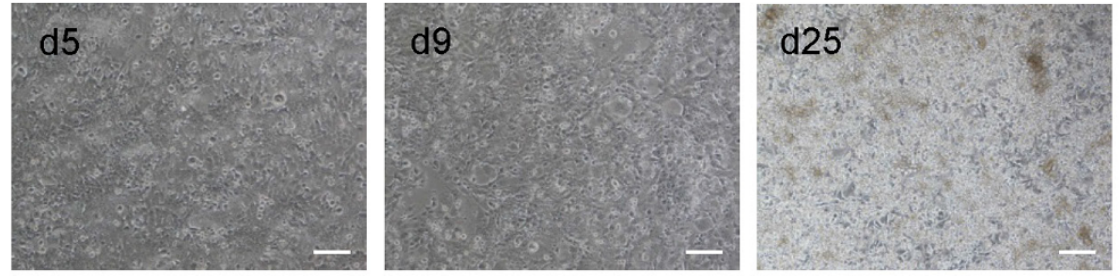

C.

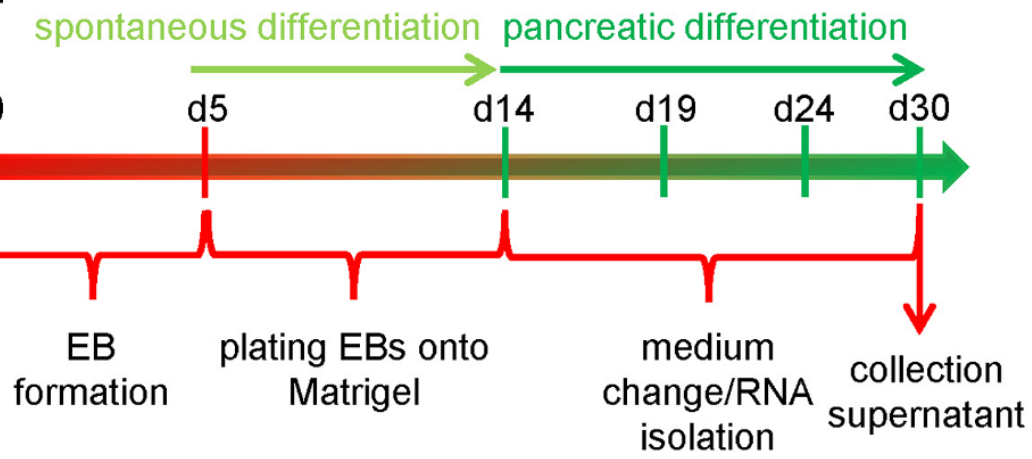

D.
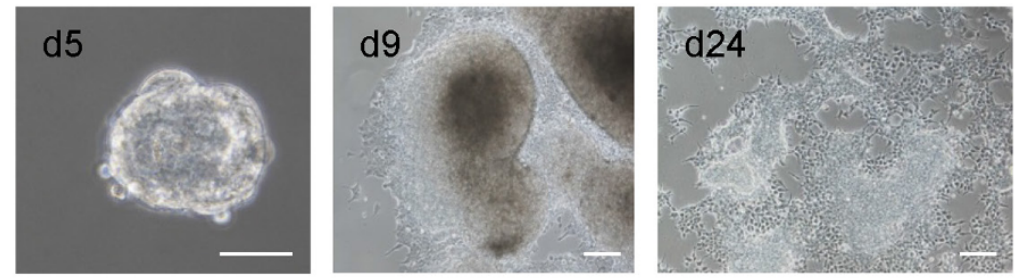

Figure 6 Differentiation of human reprogrammed cells to pancreatic lineage. (A). Schematic representation of direct differentiation method. (B). Morphological changes of HNF1A MODY Repro 1 line during direct differentiation (scale bar - $100 \mu \mathrm{m}$ ). (C). Schematic representation of embryoid body-mediated differentiation method. (D). Morphological changes of HNF1A MODY Repro 1 line during embryoid body-mediated differentiation. Representative pictures (scale bar $-100 \mu \mathrm{m}$ ).

vitro into cells originating from three different germ layers. After injections of mouse control and $\mathrm{db} / \mathrm{db}$ iPSCs into immunocompromised animals we could observe teratoma formation which indicates that obtained cell lines were pluripotent. Additionally, mouse iPSCs could be differentiated into endothelial progenitor-like cells positive for CD34 and Tie-2 markers. Importantly, such iPSc-derived db/db cells displayed impairment in angiogenic potential similar to that demonstrated by mature primary endothelial cells isolated from lungs of $\mathrm{db} / \mathrm{db}$ mice. In case of human reprogrammed cells, established control and HNF1A MODY lines did not form teratomas, nonetheless, they could be directed to differentiate toward pancreatic lineage.
To the best of our knowledge this is the first report indicating successful generation of iPSCs from $L e p^{d b / d b}$ mice which are the model of T2D. Liu et al. previously obtained and characterized iPSCs from NOD mice which are used to study pathophysiology of diabetes type $1^{19}$. Additionally, in another study such pluripotent cells were successfully differentiated into functional pancreatic beta-like insulin-producing cells which, upon transplantation into diabetic mice, reversed hyperglycemic phenotype of these animals ${ }^{25}$.

Endothelial dysfunction is an important complication associated with $\mathrm{T} 2 \mathrm{D}^{26}$. Both hyperglycemia and insulin resistance contribute to impaired physiology of endothelial cells by increasing reactive oxy- 

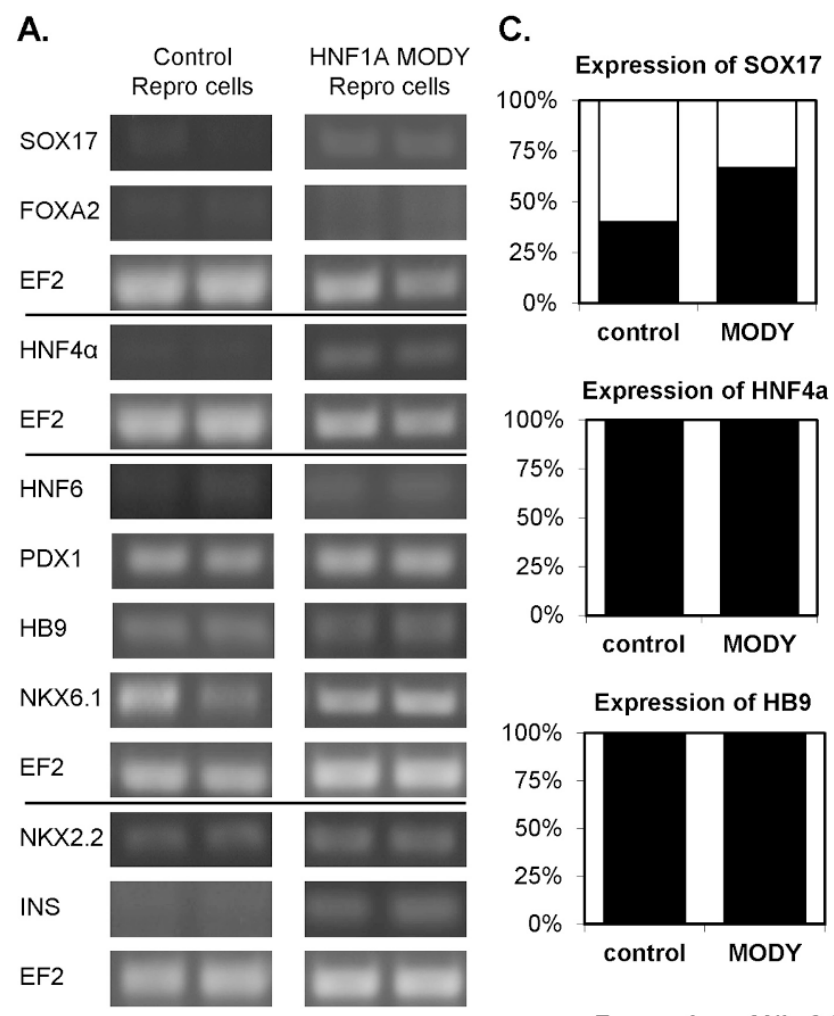

Expression of HNF4a

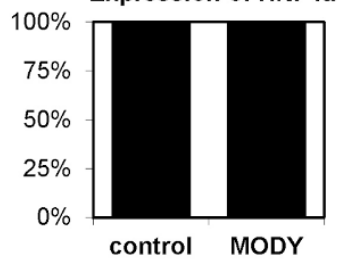

Expression of HB9

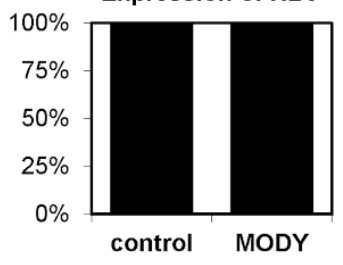

Expression of $\mathrm{Nkx2.2}$
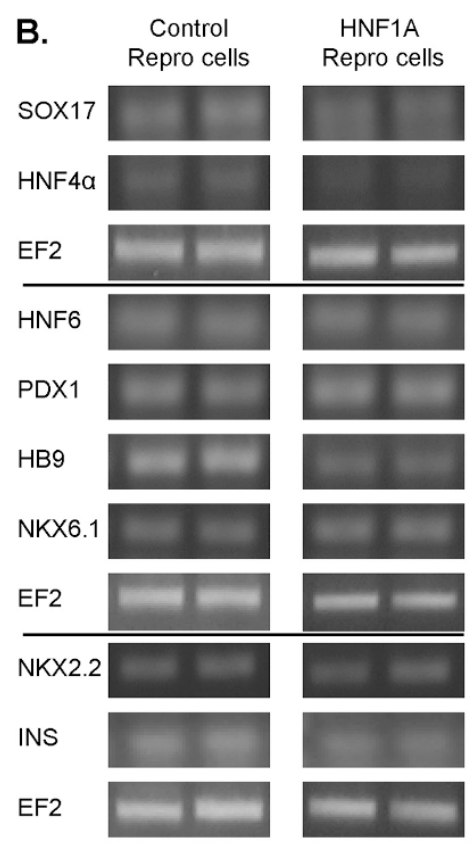

A

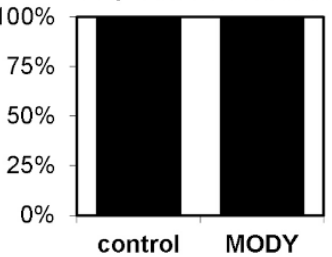

Expression of insulin

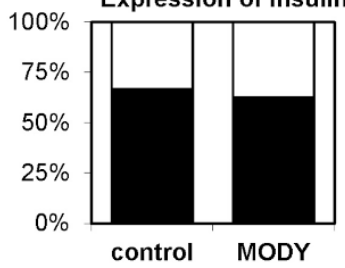

D.
Expression of FOXA2

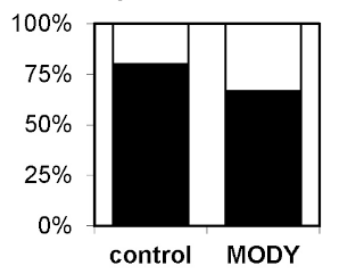

Expression of HNF6

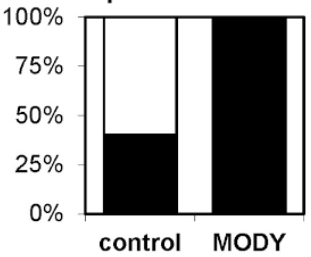

Expression of PDX1

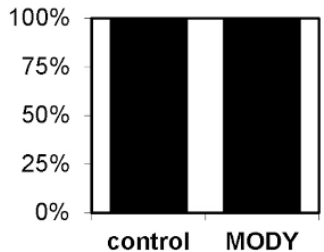

Expression of Nkx6.1

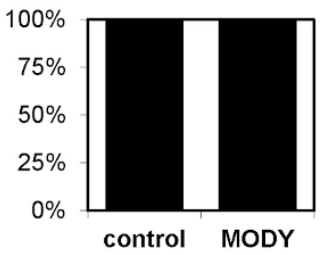

anegative

- positive

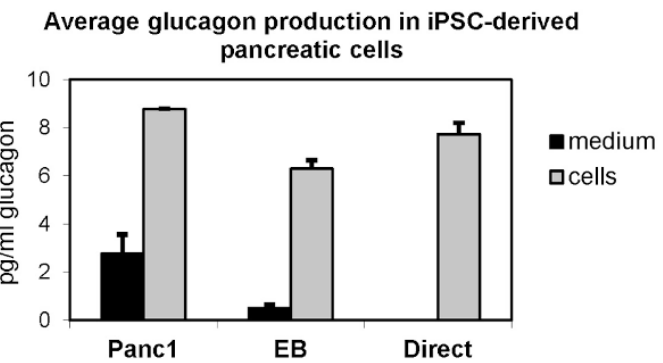

Figure $7 \mid$ Expression of markers of pancreatic differentiation in cells derived from human control and HNF1A MODY reprogrammed cells. (A). Expression of markers in cells subjected to direct differentiation method. (B). Expression of markers in cells subjected to embryoid bodies-mediated method. Agarose gel electrophoresis of representative RT-PCR products. In case of direct differentiation RT-PCR was performed for cells from each patients and in case of embryoid bodies-mediated differentiation RT-PCR was performed in duplicates. EF2 was used as a housekeeping control for each performed reaction. (C). The efficiency of detection of pancreatic differentiation markers (both differentiation methods are combined, $\mathrm{n}=3-5$ ). Percentage of positive RT-PCR results in relation to expression of EF2 housekeeping gene which was detected in all analysed samples. (D). Production of glucagon in differentiated Panc-1 cells as well as control and HNF-1A MODY reprogrammed cells differentiated with embryoid bodies-mediated method (EB) and direct method (direct). Medium - media used to perform the last step of differentiation (in case of Panc-1 cells one type of medium was utilized); cells - media collected from differentiated cells in the last day of differentiation $(n=2)$. 
gen species, production of vasoconstrictive factors, and decreasing $\mathrm{NO}$ bioavailability ${ }^{27}$. Interestingly, many reports indicated that diabetes negatively affects a heterogeneous population of endothelial (proangiogenic) progenitor cells ${ }^{28,29}$, claimed to originate from bone marrow $^{22}$. Obesity and insulin resistance, the hallmarks of T2D, lead to elevated leptin levels which in turn can result in tissue leptin resistance and endothelial dysfunction ${ }^{30}$. Additionally, leptin receptor was reported to mediate the mobilization of bone marrowderived proangiogenic progenitor cells ${ }^{31}$.

The existence of endothelial progenitors in bone marrow, specific set of markers which should be used for their characterization, and their real contribution to the process of angiogenesis is still disput$\mathrm{able}^{32}$, hence better models are required. Moreover, leptin whose signaling pathways exerted through ObR receptor are abrogated in $\mathrm{db} / \mathrm{db}$ mice, was previously demonstrated to be a proangiogenic factor $^{33,34}$ and regulator of vascular contractility ${ }^{35,36}$. On the other hand, hyperleptinemia and tissue leptin resistance, being the hallmarks of obese diabetic patient and $\mathrm{db} / \mathrm{db}$ animals, negatively affect functioning of endothelial cells and constitute important risk factors for the development of cardiovascular disease ${ }^{30}$. Taking this into consideration we decided to evaluate the potential of $\mathrm{db} / \mathrm{db}$ iPSCs to differentiate towards endothelial cells. We demonstrated here the successful generation of $\mathrm{CD} 34^{+} \mathrm{Tie}-2^{+}$population of progenitor-like cells of endothelial morphology, expressing active endothelial nitric oxide synthase, from both control and db/db iPSCs. Importantly, despite similar expression of endothelial markers, the proangiogenic activities of the $\mathrm{db} / \mathrm{db}$ iPSC-derived cells were impaired as that of the mature endothelial cells isolated from $\mathrm{db} / \mathrm{db}$ mice. This suggests that iPSC-derived endothelial-like cells may be useful in investigating the intrinsic cellular mechanisms associated with endothelial dysfunction in diabetes of different genetic background.

Since expression of CD34 is characteristic for progenitor cells ${ }^{32}$, the obtained population of differentiated cells could be considered as enriched in endothelial progenitor-like cells. The presence of Tie-2 protein, the receptor recognized by angiopoietin-1 (Ang1), a potent proangiogenic factor ${ }^{37}$, further confirms their endothelial phenotype. Interestingly, within the iPSCs colonies from which successful generation of $\mathrm{CD} 34^{+} \mathrm{Tie}-2^{+}$populations was achieved we observed lower efficiency of differentiation in $\mathrm{db} / \mathrm{db}$ cells. This might be in line with the decreased expression of heme oxygenase-1, angiotensinogen and proteoglycan -4 in $\mathrm{db} / \mathrm{db}$ iPSCs. Among these factors, heme oxygenase- 1 is required for proper angiogenic function of mature endothelial cells ${ }^{38}$ and bone marrow-derived proangiogenic cells [ref. 22, reviewed in ref. 39]. The role of angiotensinogen and proteoglycan-4 in endothelial differentiation and physiology has not been extensively studied, however, they can facilitate development of hemangioblasts ${ }^{20,21}$.

Differentiated $\mathrm{db} / \mathrm{db}$ cells exhibited impaired angiogenic potential in endothelial sprouting assay. Schiekofer et al. demonstrated that $\mathrm{db} / \mathrm{db}$ mice have reduced basal capillary density and impaired ischemia-induced vascular remodeling which was associated with altered expression patterns of angiogenesis-related factors in $\mathrm{db} / \mathrm{db}$ animals ${ }^{40}$. We also showed that proangiogenic cells derived from bone marrow of $\mathrm{db} / \mathrm{db}$ mice display lower migratory capacity and reduced formation of capillaries both in 2D culture on Matrigel and in 3D culture of spheroids embedded in collagen ${ }^{41}$. Our present results could additionally indicate that leptin plays an important role in embryonic development of endothelial cells, although more studies are necessary to draw reliable conclusions.

In contrast to human T2D, Maturity Onset Diabetes of the Young 3 is a monogenic disease and results from the mutations in HNF- $1 \alpha$ transcription factor. Although impaired function of only one protein is linked to the pathophysiology of HNF1A MODY, the molecular mechanisms responsible for the clinical outcome of the patients are not fully understood, mainly due to the poor accessibility of affected tissues. Generation of patient-specific iPSCs could be an important step to address this issue. Indeed, HNF1A MODY iPSCs have been already obtained by Teo et al. who utilized Cre-excisible STEMCCA vector $^{17}$. However, the authors did not perform pancreatic differentiation of those cells.

The reprogrammed cells obtained in our work expressed pluripotency markers like OCT3/4A, SSEA4, TRA-1-60 and TRA-1-81 and differentiated in vitro towards cells originating from three germ layers. However, despite positive staining for pluripotency and lineage-commitment markers, they were not able to form teratomas after subcutaneous administration into immunocompromised mice. This could indicate that the obtained cell lines represent only partially reprogrammed cells ${ }^{42}$. Alternatively, our method of establishing stable iPSC lines could result in heterogeneous population of partially and fully reprogrammed cells with varying proportions of both populations. In this scenario, the lack of teratoma formation could result from too low number of bona fide iPSCs among injected cells.

Our data indicate that obtained iPSCs could be successfully differentiated into cells of pancreatic lineage, expressing the insulin gene and producing glucagon. Importantly, in view of this differentiation potential, lack of teratoma formation can be considered as beneficial characteristic increasing the safety of possible future clinical utilization of such cells. Utilization of such patient-specific cells to generate cells of pancreatic lineages would provide an excellent tool to study molecular mechanisms responsible for impaired insulin production in HNF1A MODY patients and the exact role of HNF- $1 \alpha$ in this process. The proof-of-concept of such approach was provided by Hua et al. with iPSCs derived from MODY2 patients who carry the mutations in glucokinase encoding gene ${ }^{18}$. Those cells could be differentiated into mature $\beta$ cells with similar efficiency as control counterparts and recapitulated the clinical phenotype of the patients. This study highlights also the important issue of utilization of proper control cells which the authors generated by targeted gene modifications with zinc finger nucleases. Such approach enables the direct comparison of mutated and corrected cells with the same genetic background. In our study, the control cells were derived from nondiabetic individuals so the possibility of differences originating from different genetic background of HNF1A MODY reprogrammed cells should be taken into consideration. Nevertheless, the level of expression of insulin gene in our in vitro differentiated pancreatic lineage was too low for reliable quantitative comparisons and mechanistic study of molecular pathways. One can suppose that the final steps of differentiation within in vivo niche can be more effective ${ }^{18}$

During the revision of this manuscript, Pagliuca et al. reported novel in vitro differentiation approach leading to generation of functional human pancreatic $\beta$ cells from pluripotent stem cells ${ }^{24}$. Importantly, such stem-cell-derived glucose-responsive and monohormonal insulin-producing $\beta$ cells demonstrated features of mature adult counterparts. This is of great importance since previous protocols, including those utilized in this study enabled predominantly to obtain immature, polyhormonal cells ${ }^{24,43}$. Accordingly, our differentiation approaches led to generation of cells expressing insulin and glucagon.

In summary we report in this study the generation of mouse $\mathrm{db} / \mathrm{db}$ iPSCs as well as patient-specific HNF1A MODY reprogrammed cells which could be considered as important tools for investigation of molecular mechanisms responsible for pathophysiology of different types of diabetes. Further studies should elucidate the potential of such cells in modeling clinical phenotypes observed in diabetic patients.

\section{Methods}

Mice. $L e p^{d b / d b}$ and control mice were purchased from Charles River. C57BL/6J mice (Charles River) were used to prepare mouse embryonic fibroblasts constituting a feeder layer for the growth of iPSCs. Foxn1nu immunodeficient mice utilized in teratoma formation assay were purchased from Harlan Laboratories. Mice were maintained under the specific pathogen free conditions, in individually ventilated 
cages, with full access to food and water. All procedures involving the use of animals were performed according to approved guidelines. All animal experiments were approved by the Local Ethical Committee for Animal Research at the Jagiellonian University (approval no. 51/2012, 101/2013, 208/2013).

Preparation and culture of murine fibroblasts. Somatic fibroblasts were isolated from tails of 3-4 month old $L e p^{d b / d b}(\mathrm{~N}=5)$ and control mice $(\mathrm{N}=5)$. Tails were excised, peeled, minced into smaller pieces and subsequently digested in collagenase II solution ( $1.5 \mathrm{mg} / \mathrm{mL}$, Life Technologies) for 3 hours. Tissue fragments were centrifuged and seeded onto gelatin-coated wells of 6-well plates in DMEM (Lonza) containing 10\% FBS (Lonza), penicillin $(100 \mathrm{U} / \mathrm{mL})$ and streptomycin $(100 \mu \mathrm{g} / \mathrm{mL}$, both from Sigma-Aldrich). The same medium was used for further culture of the cells.

Mouse embryonic fibroblasts (MEFs) were obtained from 13-15 day old C57BL/6 J embryos. After isolation from the uterus, embryos were washed twice in PBS and subjected to the head and visceral tissues removal. The remaining parts were minced and digested in $0.25 \%$ trypsin/EDTA solution ( $1 \mathrm{~mL}$ per embryo, Lonza) for 2 hours. Subsequently, fresh DMEM medium containing $10 \% \mathrm{FBS}$, penicillin $(100 \mathrm{U} / \mathrm{mL})$ and streptomycin $(100 \mu \mathrm{g} / \mathrm{mL})$ was added $(5 \mathrm{~mL}$ per embryo), obtained cells and tissue fragments were centrifuged $\left(200 \times g, 5\right.$ minutes) and seeded onto $75 \mathrm{~cm}^{2}$ flasks. The same type of medium was used for further culture of MEFs. For mitotical inactivation of these cells, mitomycin C (Sigma-Aldrich) was added to the culture medium at the concentration of $10 \mu \mathrm{g} / \mathrm{mL}$ for 3 hours. Subsequently, inactivated MEFs (iMEF) were seeded to constitute a feeder layer for growth of either mouse iPSCs $\left(1.5 \times 10^{5}\right.$ cells/ well of 6-well plate) or human $\left(3 \times 10^{5}\right.$ cells/well of 6-well plate) reprogrammed cells.

Patient selection, skin biopsies and culture of human primary fibroblasts. All procedures have been performed according to the approved guidelines of Local Bioethical Committee at the Jagiellonian University, after receiving the informed consent of all the subjects (Local Bioethical Committee's approval no. KBET/43/B/ 2012). Patients suffering from HNF1A MODY were recruited in the Clinic of Metabolic Disease, Collegium Medicum of Jagiellonian University, Krakow. HNF1A MODY Repro 1 cell line was derived from 57 years old female with substitution of cytosine 811 with thymidine within exon 4 of HNF1A gene leading to replacement of arginine with tryptophan in protein sequence. HNF1A MODY Repro 2 cell line was derived from 30 years old male with deletion of thymidine 1137 within exon 6 of HNF1A gene leading to the shift in protein coding frame. $6 \mathrm{~mm}$ skin biopsies were transferred into PBS $\left(\mathrm{Mg}^{2+}\right.$ and $\mathrm{Ca}^{2+}$ free) supplemented with penicillin $(100 \mathrm{U} / \mathrm{mL})$, streptomycin $(100 \mu \mathrm{g} / \mathrm{mL})$ and amphotericin B $(10 \mu \mathrm{g} / \mathrm{mL}$, Sigma-Aldrich). Dermis was subsequently separated from epidermis and cut into small pieces which were digested in collagenase II $(2.75 \mathrm{mg} / \mathrm{mL})$ and DNaseI $(1 \mathrm{mg} / \mathrm{mL}$, Merck) solution. Released cells and tissue fragments were then centrifuged $(200 \times g, 5$ minutes $)$, suspended in fresh DMEM medium containing $10 \% \mathrm{FBS}$, penicillin $(100 \mathrm{U} / \mathrm{mL})$, streptomycin $(100 \mu \mathrm{g} / \mathrm{mL})$ and amphotericin $\mathrm{B}(10 \mu \mathrm{g} / \mathrm{mL})$ and seeded on a gelatincoated wells of 6-well plate. The same medium was used for further culture of human fibroblasts.

Control, non-diabetic samples were obtained in the Clinic of Surgery, Collegium Medicum of Jagiellonian University, Krakow, from two non-diabetic patients undergoing routine surgery. For this purpose, surgical incisions were prolonged for 4-6 mm, and skin biopsies were collected. Further isolation of human fibroblasts was performed following the same procedures as MODY samples.

Production of VSV-G pseudotyped lentiviral vectors. Production of VSV-G pseudotyped lentiviral vectors was performed according to the previously described protocol $^{44}$. Briefly, $7 \times 10^{6} 293 \mathrm{~T}$ cells (kindly gifted by dr. Maciej Wiznerowicz, Greater Poland Cancer Center, Poznan, Poland) were seeded onto $10 \mathrm{~cm}$ dishes in the DMEM medium containing $10 \%$ FBS, penicillin $(100 \mathrm{U} / \mathrm{mL})$ and streptomycin $(100 \mu \mathrm{g} / \mathrm{mL})$ and subsequently subjected to the triple plasmid transfection with polyethylenimine (PEI, Polysciences Inc.) as a transfectant reagent. Reprogramming vectors were produced utilizing hSTEMCCA plasmid construct containing four transcription factors: OCT3/4A, KLF4, SOX2 and c-MYC within one expression cassette (kindly provided by dr. Gustavo Mostoslavsky, Boston University, USA ${ }^{45}$ ) whereas in case of control vectors, FUGW plasmid, harboring GFP cDNA, was used (Addgene 14883). Additionally, psPAX2 and pMD2.G plasmids (kindly provided by dr Maciej Wiznerowicz, Greater Poland Cancer Center) served as a source of tat, rev, gag/pol and VSV-G, respectively. $48 \mathrm{~h}$ post-transfection, media containing vectors were collected, filtered through $0.8 \mu \mathrm{m}$ filters (Millipore), aliquoted, and frozen at $-80^{\circ} \mathrm{C}$.

Reprogramming of mouse and human fibroblasts. $2.5 \times 10^{4}$ murine fibroblasts isolated from wild type as well as $L e p^{d b / d b}$ mice were seeded on wells of 24 -well plate and transduced with either reprogramming (hSTEMMCA) or control, FUGW vectors, in the presence of $4 \mu \mathrm{g} / \mathrm{mL}$ of polybrene (Sigma-Aldrich). $24 \mathrm{~h}$ posttransduction media containing vector particles were replaced with fresh culture media, in which the cells were grown until full confluency. Subsequently, fibroblasts were trypsinized ( $0.25 \%$ trypsin/EDTA solution) and transferred to the 6-well plates covered with mitotically inactivated MEFs in the iPSCs medium consisting of DMEM supplemented with $20 \% \mathrm{FBS}$, penicillin $(100 \mathrm{U} / \mathrm{mL})$, streptomycin $(100 \mu \mathrm{g} / \mathrm{mL}), 1 \%$ non-essential amino acids (Life Technologies), $0.1 \mathrm{mM} 2$-mercaptoethanol (Life Technologies) and $1000 \mathrm{U} / \mathrm{ml}$ leukemia inhibitory factor (LIF, Millipore). The medium has been changed daily until the colonies resembling embryonic stem cells emerged. Colonies were subsequently picked, trypsinized $(0.25 \%$ trypsin/EDTA solution) and seeded on the new wells of 24 -well plate coated with mitotically inactivated MEFs. Control and Lep $p^{d b / d b}$ iPSCs were further expanded and characterized.

For reprogramming of human fibroblasts, $2.5 \times 10^{4}$ control and HNF1A MODY cells were seeded on gelatin-coated (Sigma-Aldrich) 24-well plates and transduced with either reprogramming (hSTEMMCA) or control, FUGW vector in the presence of $4 \mu \mathrm{g} / \mathrm{mL}$ of polybrene (Sigma-Aldrich). $24 \mathrm{~h}$ post-transduction media containing vector particles were replaced with human iPSC medium consisting of KnockOut DMEM (Life Technologies) supplemented with 20\% KnockOut Serum Replacement (KSR, Life Technologies), penicillin (100 U/mL), streptomycin $(100 \mu \mathrm{g} / \mathrm{mL}), 1 \%$ non-essential amino acids, $0.1 \mathrm{mM} 2$-mercaptoethanol and $10 \mathrm{ng} / \mathrm{ml}$ of human bFGF (PeproTech). On $6^{\text {th }}$ day of reprogramming the cells were reseeded on either mitotically inactivated MEF- or Matrigel- (BD Biosciences) coated $60 \mathrm{~mm}$ dishes. The cells were fed every other day until mature colonies resembling human embryonic stem cells emerged.

Picked colonies were mechanically dissociated and seeded onto new Matrigel- or iMEF-coated 24-well plates. For the improvement of survival the ROCK inhibitor $(10 \mu \mathrm{M}, \mathrm{Abcam})$ was added to the iPSC culture medium ${ }^{46}$. The separation of reprogrammed cells was also carried out by exploiting faster adherence of nonreprogrammed fibroblasts to gelatin-coated surface. Briefly, cell suspension, dissociated by Accutase (GE Healthcare) was placed on gelatin coated dishes for 35 minutes. Floating cells enriched in human reprogrammed cells were further cultured on Matrigel-coated dishes. This procedure was repeated 3-4 times to ensure sufficient removal of non-reprogrammed cells. Reprogrammed lines from two control individuals (named Ctr Repro 1 and 2) and two HNF1A MODY patients (named HNF1A MODY Repro 1 and 2) were subsequently expanded and characterized.

Spontaneous differentiation of mouse iPSCs and human reprogrammed cells embryoid body formation. To verify the pluripotency of obtained mouse iPSCs and human reprogrammed cells, in a first step in vitro spontaneous differentiation was performed. Briefly, mouse iPSCs and human reprogrammed cells growing on iMEFcoated wells suspended in either mouse iPSC differentiation medium (DMEM supplemented with $20 \%$ FBS, penicillin (100 U/mL), streptomycin $(100 \mu \mathrm{g} / \mathrm{mL}), 1 \%$ non-essential amino acids and $0.1 \mathrm{mM} 2$-mercaptoethanol) or human iPSC differentiation medium (KnockOut DMEM supplemented with 20\% KnockOut Serum Replacement, penicillin $(100 \mathrm{U} / \mathrm{mL})$, streptomycin $(100 \mu \mathrm{g} / \mathrm{mL}), 1 \%$ nonessential amino acids and $0.1 \mathrm{mM} 2$-mercaptoethanol) and seeded on non-adherent $100 \mathrm{~mm}$ dishes. After 5 days, mouse EBs were transferred onto gelatin-coated 48-well plates and further cultured for 12 days with daily medium change. Similarly, human EBs were transferred after 5-8 days on Matrigel-coated dishes and cultured for 5-9 days. Both mouse and human differentiated cells were subsequently immunofluorescently analyzed for expression of markers characteristic for cells originating from endo-, ecto- and mesoderm.

Teratoma formation assay. Mouse iPSCs were trypsinized and reseeded on gelatincoated wells for $1 \mathrm{~h}$ to deplete the population of iMEFs. Floating cells were collected, centrifuged and resuspended in DMEM supplemented with $10 \%$ FBS, penicillin $(100 \mathrm{U} / \mathrm{mL})$, and streptomycin $(100 \mu \mathrm{g} / \mathrm{mL}) .1 .5 \times 10^{6}$ cells were injected subcutaneously into dorsal flank of immunocompromised Foxlnu mice. After approximately 8 weeks tumors were excised, embedded in paraffin and subjected to histological analysis with hematoxilin and eosin staining.

Human reprogrammed cells were detached with Accutase, centrifuged and resuspended in human iPSCs differentiation medium. 1-2 $\times 10^{6}$ cells were injected subcutaneously into dorsal flank of immunocompromised Foxlnu mice. After approximately 8 weeks the sole resulting tumor were excised, embedded in paraffin and subjected to histological analysis with hematoxilin and eosin staining.

Differentiation of mouse iPSCs into endothelial cells. Mouse iPSCs were trypsinized and reseeded on gelatin-coated wells for $1 \mathrm{~h}$ to deplete the population of iMEFs. Floating cells were collected, centrifuged, resuspended in $\alpha$-MEM (Lonza) supplemented with $10 \%$ FBS, penicillin (100 U/mL), streptomycin $(100 \mu \mathrm{g} / \mathrm{mL}), 1 \%$ non-essential amino acids and $0.1 \mathrm{mM} 2$-mercaptoethanol (EDM, endothelial differentiation medium), and subsequently seeded on 12-well plates coated with collagen IV (Sigma-Aldrich; $5 \mu \mathrm{g} / \mathrm{cm}^{2}$, diluted in $50 \mathrm{mM}$ hydrochloric acid). Cells were cultured for 4 days and then transferred to 12 -well plates coated with fibronectin (Sigma-Aldrich; $20 \mu \mathrm{g} / \mathrm{mL}, 15-30$ minutes at $37^{\circ} \mathrm{C}$ ) in EDM medium supplemented with $50 \mathrm{ng} / \mathrm{mL}$ VEGF (Sigma-Aldrich). Further passaging was performed whenever cells reached around $90 \%$ confluency. After approximately 30-60 days, when majority of cells acquired endothelial-like phenotype $\left(\mathrm{CD} 34^{+} \mathrm{Tie}-2^{+33}\right)$, the medium was changed to EGM-2MV (Lonza) and the cells were further cultured for the immunophenotyping and functional assays. Differentiated cells could be kept in culture for at least 130 days without changes in the morphology, phenotype or growth capacity.

Isolation of lung primary endothelial cells. Lungs from 5 control, wild type and 6 Lep ${ }^{d b / d b}$ mice were cut in small pieces and digested in $1 \mathrm{U} / \mathrm{mL}$ of dispase for $1 \mathrm{~h}$ at $37^{\circ} \mathrm{C}$ with agitation from time to time. The resulting cell suspension was filtered and stained with anti-CD34-FITC conjugated antibody (BD Bioscience). Subsequently cells were incubated with anti-FITC magnetic beads (Myltenyi Biotech) for 15 minutes and separated on AutoMACS (Myltenyi Biotech). CD34 positive cells were then counted and seeded in EGM-2MV with methylcellulose in U-shaped 96-well plate for in vitro endothelial sprouting assay. No spheres could be obtained from 2 $L e p^{d b / d b}$ mice. In the rest of the sorted cells compact spheres could be formed after 5 
days in culture. The resulting spheres were embedded in collagen I and the sprouting was assessed after $24 \mathrm{~h}$.

Flow cytometry. In order to immunophenotype the cells during endothelial differentiation, they were detached with Accutase (Cytogen), washed with PBS and resuspended in PBS with 2\% FBS. Subsequently, the cells were incubated with FcR blocking reagent (Miltenyi Biotech) for 10 minutes at $4{ }^{\circ} \mathrm{C}$ followed by addition of specific antibodies conjugated with fluorochromes: CD34-FITC (BD Biosciences) and Tie-2-APC (Biolegend). After 30 minutes of incubation at $4{ }^{\circ} \mathrm{C}$ the cells were washed with PBS, resuspended in PBS supplemented with $2 \%$ FBS and acquired on LSRII flow cytometer (BD Biosciences). Appropriate single stained samples were used for compensation of different fluorochromes. Results were analyzed by Diva software (BD Biosciences).

Endothelial sprouting assay. To form endothelial spheres, differentiating iPSCs at day 120 of culture were detached with Accutase and transferred to $10 \mathrm{~mL}$ of medium containing methyl cellulose [composed of $10 \mathrm{~mL}$ of methyl cellulose (Sigma-Aldrich; $100 \%$ ) and $40 \mathrm{~mL}$ of EGM-2MV medium] to obtain concentration of $7500 \mathrm{cells} / \mathrm{mL}$. Subsequently, 750 cells/well were seeded on U-shaped 96-well plate in $100 \mu \mathrm{l}$ of medium. The plate was incubated at $37^{\circ} \mathrm{C}$ and the formation of spheres was assessed after $1-3$ days.

After the spheres were formed they were embedded in collagen type I (BD Biosciences) for evaluation of sprouting capability. Briefly, the spheres were centrifuged ( $45 \times g$, 3 minutes, room temperature) and resuspended in $500 \mu \mathrm{L}$ of methyl cellulose supplemented with $30 \%$ FBS. Subsequently, $500 \mu \mathrm{L}$ of HBSS containing phenol red (Sigma-Aldrich) were mixed with $4 \mathrm{~mL}$ of $100 \%$ collagen I solution followed with its neutralization with sterile $200 \mathrm{mM} \mathrm{NaOH}$. $500 \mu \mathrm{L}$ of collagen solution was mixed with $500 \mu \mathrm{L}$ of sphere suspension and immediately poured on 24 well plate. After 15 minutes of incubation at $37^{\circ} \mathrm{C}$, the wells were covered with $200 \mu \mathrm{L}$ of EGM-2MV medium. The sprouting was assessed after $24 \mathrm{~h}$ and $48 \mathrm{~h}$ using an inverted microscope.

Nitric oxide production. The production of $\mathrm{NO}$ was measured in the culture medium of differentiated cells at day 130 of culture, using gas-phase chemiluminescence reaction. Nitrite, the major oxidation product of $\mathrm{NO}$ in the absence of oxyhemoglobin or superoxide anion, is formed when NO reacts with dissolved oxygen. Therefore the nitrite formed in the medium was reduced in a solution of acetic acid in the presence of iodide ${ }^{47}$ and the measurement was performed with 280i Nitric Oxide Analyzer ( $\mathrm{NOA}^{\mathrm{TM}}$, Sievers) equipped with high sensitivity detector for NO.

Pancreatic differentiation - direct method. The direct differentiation approach follows a modified protocol by Maehr et al. ${ }^{48}$. Accordingly, human reprogrammed cells (Ctr Repro 1 and 2 as well as HNF1A MODY Repro 1 and 2) were seeded onto Matrigel coated 12-well plates. The cells were cultured in human iPSCs medium until $80 \%$ confluency was observed followed by the first change to differentiation medium. During the four differentiation stages the differentiation medium was replaced six times: at day $1^{\text {st }}$ it composed of Advanced RPMI (Life Technologies) supplemented with Wnt3a (25 ng/mL, Sigma-Aldrich), Activin A (100 ng/mL, PeproTech), $1 \%$ Glutamax (Life Technologies), penicillin $(100 \mathrm{U} / \mathrm{mL})$ and streptomycin $(100 \mu \mathrm{g} /$ $\mathrm{mL}$ ); on day $3^{\text {rd }}$ it composed of Advanced RPMI supplemented with $0.2 \%$ FBS, Activin A (100 ng/mL), $1 \%$ Glutamax, penicillin $(100 \mathrm{U} / \mathrm{mL})$ and streptomycin $(100 \mu \mathrm{g} /$ $\mathrm{mL}$ ); on day $5^{\text {th }}$ it composed of Advanced RPMI supplemented with $2 \%$ FBS, FGF10 (50 ng/mL, PeproTech), $25 \mu$ M KAAD-Cyclopamine (Sigma-Aldrich), 1\% Glutamax, penicillin $(100 \mathrm{U} / \mathrm{mL})$ and streptomycin $(100 \mu \mathrm{g} / \mathrm{mL})$, on day $9^{\text {th }}$ it composed of DMEM supplemented with FGF10 (50 ng/mL), $25 \mu \mathrm{M} \mathrm{KAAD-}$ Cyclopamine, $2 \mu \mathrm{M}$ retinoic acid (Sigma-Aldrich), B27 supplement (1x, Life Technologies), $1 \%$ Glutamax, penicillin $(100 \mathrm{U} / \mathrm{mL})$ and streptomycin $(100 \mu \mathrm{g} / \mathrm{mL})$; on day $13^{\text {th }}$ it composed of DMEM supplemented with FGF10 $(50 \mathrm{ng} / \mathrm{mL}), 300 \mathrm{nM}$ Indolactam V (Sigma-Aldrich), B27 supplement (1x, Life Technologies), 1\% Glutamax, penicillin $(100 \mathrm{U} / \mathrm{mL})$ and streptomycin $(100 \mu \mathrm{g} / \mathrm{mL})$; and on day $19^{\text {th }}$ it composed of DMEM supplemented with $10 \mu$ M DAPT (Sigma-Aldrich), B27 supplement (1x), 1\% Glutamax, penicillin $(100 \mathrm{U} / \mathrm{mL})$ and streptomycin $(100 \mu \mathrm{g} /$ $\mathrm{mL}$ ). With every step the morphological changes were documented and RNA was isolated.

Pancreatic differentiation - embryoid body-based method. The differentiation approach based on a prior EBs formation was performed according to the modified protocol described in Schroeder et al. ${ }^{49}$. Ctr Repro 2 and HNF1A MODY Repro 1 were used in this experiment. EBs were formed as described for spontaneous

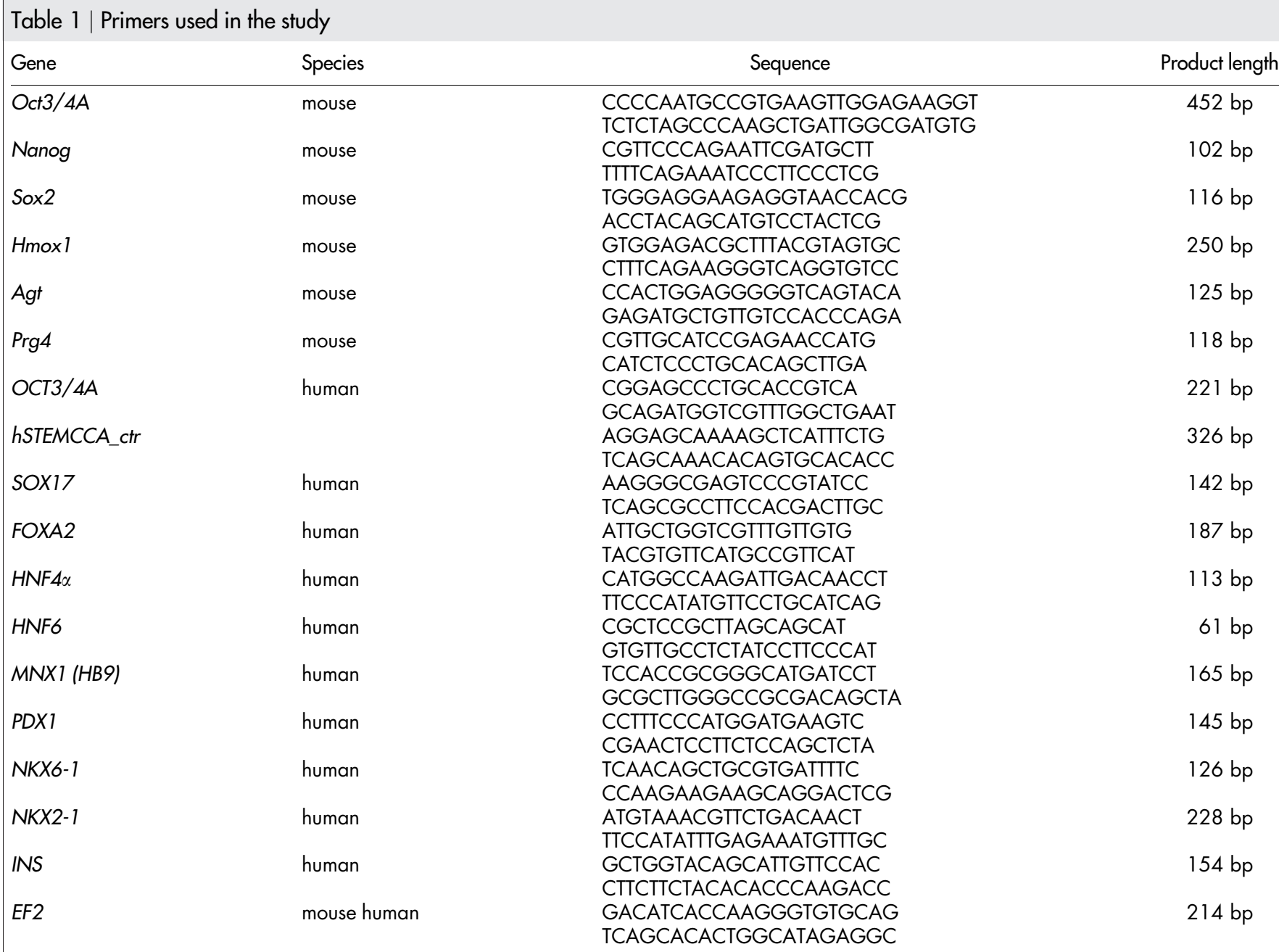


differentiation of human reprogrammed cells and cultured in non-adherent conditions for 5 days. Subsequently they were seeded onto Matrigel-coated dishes $(60 \mathrm{~mm})$ for further 9 days in the same medium during which spontaneous differentiation occurred. On day $14^{\text {th }}$ the cells were washed 2 times with PBS, trypsinized and removed from the dish surface with a cell scraper. Collected cells were suspended in differentiation medium composed of DMEM/F12 (Lonza) supplemented with $10 \%$ FBS, $100 \mu \mathrm{M}$ putrescine (Sigma-Aldrich), $20 \mathrm{nM}$ progesterone (Sigma-Aldrich), laminin ( $1 \mu \mathrm{g} / \mathrm{mL}$, Sigma-Aldrich), insulin (25 $\mu \mathrm{g} /$ $\mathrm{mL}$, Sigma-Aldrich), $30 \mathrm{nM}$ sodium selenite (Sigma-Aldrich), transferrin $(50 \mu \mathrm{g} / \mathrm{mL}$, Sigma-Aldrich), B27 supplement $(1 \mathrm{x})$, penicillin $(100 \mathrm{U} / \mathrm{mL})$ and streptomycin $(100 \mu \mathrm{g} / \mathrm{mL})$ and seeded onto collagen I coated dishes (1:70 in $0.2 \mathrm{~N}$ acetic acid). Differentiation medium was changed every other day and RNA isolation was performed on day 19, 24 and 30.

Differentiation of Panc-1 pancreatic cancer cell line. Panc-1 cells (ATCC, CRL$1469)$ were cultured in DMEM medium containing $10 \% \mathrm{FBS}$, penicillin $(100 \mathrm{U} / \mathrm{mL})$ and streptomycin $(100 \mu \mathrm{g} / \mathrm{mL})$ and differentiated toward insulin- and glucagonexpressing cells according to Suzuki J et al. protocol ${ }^{50}$. Briefly, $1 \times 10^{6}$ cells cultured on 6-well plate were washed with PBS and treated for $30 \mathrm{~s}$ with $0.05 \%$ trypsin/EDTA solution at room temperature. Trypsin was removed, cells were washed three times with PBS and subsequently cultured for 6 days in DMEM/F12 medium containing $17.5 \mathrm{mM}$ glucose and 1\% BSA. Media were collected and subjected to enzyme immunoassay (EIA) for measurement of glucagon concentration.

Enzyme immunoassay (EIA). EIA assay (Sigma-Aldrich) for measurement of glucagon concentration was performed according to manufacturer's protocol. Media collected from differentiated Panc- 1 cells and from the last day of differentiation of control and HNF1A MODY reprogrammed cells via direct and EB-mediated protocols were used.

Isolation of RNA, RT-PCR and real-time qPCR. Total cellular RNA was isolated utilizing the phenol/chloroform extraction. To ensure complete removal of genomic DNA contamination samples were treated with DNase I (Life Technologies). Reverse transcription was performed with M-MuLV Reverse Transcriptase (Thermo Scientific) and oligo(dT) primers (Promega). PCR reaction was performed using Taq polymerase (Promega) under following conditions: $95^{\circ} \mathrm{C}$ for 5 minutes, 40 cycles of $95^{\circ} \mathrm{C}$ for 30 seconds, annealing temperature for 60 seconds and $72^{\circ} \mathrm{C}$ for 45 seconds, with final elongation at $72^{\circ} \mathrm{C}$ for 5 minutes. The PCR products electrophoresis was performed in 2\% agarose gel. Quantitative real-time PCR with melt curve analysis of amplified products was performed with StepOne Plus cycler (Applied Biosystems) and SYBR ${ }^{\circledR}$ Green JumpStart ${ }^{\mathrm{TM}}$ Taq ReadyMix ${ }^{\mathrm{TM}}$ (Sigma-Aldrich).

In murine iPSCs the expression of Oct3/4A, Nanog, Sox2, Hmox1, Prg4 and Agt was determined by quantitative RT-PCR, while in human reprogrammed cells OCT3/4A and markers of pancreatic differentiation were checked ${ }^{48}$. The applied PCR program for detection of pancreatic differentiation markers followed the same setting as for OCT3/4A except for the annealing temperature which was reduced to $54^{\circ} \mathrm{C}$ and additionally, $6 \mu \mathrm{L}$ (instead of $2 \mu \mathrm{L}$ ) of cDNA samples were used. After first examinations the markers with low gene expression, i.e. SOX17 and INS were also amplified by PCR using a highly sensitive DNA polymerase (Q5 ${ }^{\circledR}$ High-Fidelity DNA Polymerase [2000 U/mL], New England Biolabs). In case of direct differentiation RTPCR was performed for cells from each patients and in case of embryoid bodiesmediated differentiation RT-PCR was performed in duplicates. Additionally, silencing of the hSTEMCCA vector was tested by amplification of sequence specific for transgene cassette with primers designed to recognize c-MYC (forward primer) and WPRE (reverse primer) part of the vector construct within the cellular transcripts ${ }^{51}$. EF2 was used as the housekeeping gene. The sequences of primers used in the study are provided in Table 1 .

Immunofluorescent analysis. Mouse iPSCs and human reprogrammed cells as well as differentiating cells growing in 48 -well plates were washed with PBS, fixed with $4 \%$ paraformaldehyde for 10 minutes in room temperature and permeabilized with $0.1 \%$ Triton-X100 in PBS (10 minutes, room temperature). Cells were washed three times with PBS, blocked for $1 \mathrm{~h}$ in room temperature with $4 \%$ BSA in PBS solution and incubated with the primary antibodies overnight at $4{ }^{\circ} \mathrm{C}$. The following primary antibodies were used: Oct3/4A (1:200, Santa Cruz Biotechnology), Nanog (1:200, Abcam), SSEA-1 (1:200, Millipore), SSEA-4, TRA-1-60, TRA-1-81 (1:100, Millipore), Nestin, Vimentin (1:200, Abcam), Neurofilament heavy chain (1:1000, Abcam), smooth muscle actin (1:100, Abcam), GATA-4 (1:50 for human and 1:200 for murine cells, Santa Cruz Biotechnology), Nkx2.5 (1:200, Santa Cruz Biotechnology), vWF (1:100, Abcam), Flt-1 (1:100, Abcam), phospho eNOS (1:100, Abcam).

Subsequently, cells were washed 5 times with PBS and incubated with secondary antibodies (AlexaFluor, Life Technologies) for $1 \mathrm{~h}$ in room temperature. This was followed by incubation with $1 \mu \mathrm{g} / \mathrm{mL}$ of Hoechst 33342 in PBS for 10 minutes in room temperature and 4 washing steps with PBS. Cells were eventually visualized under fluorescent microscope (Nikon Eclipse TS100). Additionally, mouse iPSCs were stained with CDyl (kindly provided by dr Young-Tae Chang, Department of Chemistry, National University of Singapore), a fluorescent dye which selectively marks mouse and human pluripotent stem cells ${ }^{52}$. For this purpose, iPSCs were incubated with $0.1 \mu \mathrm{g} / \mathrm{mL}$ of CDyl diluted in iPSCs culture medium for $1 \mathrm{~h}$ at $37^{\circ} \mathrm{C}$. Cells were than washed with PBS and further cultured for $2 \mathrm{~h}$ in fresh medium. Colonies were visualized under fluorescent microscope.
Statistical analysis. Data are presented as mean + SEM. Unpaired two-tailed t-test or exact Fisher test were used to analyze statistical significance. Results were considered as significant at $p<0.05$.

1. Danaei, G. et al. National, regional, and global trends in fasting plasma glucose and diabetes prevalence since 1980: systematic analysis of health examination surveys and epidemiological studies with 370 country-years and 2.7 million participants. Lancet 378, 31-40 (2011).

2. Petersen, K. F. \& Shulman, G. I. Etiology of insulin resistance. Am J Med 119(Suppl 1), 10-16 (2006).

3. Kahn, C. R. Banting Lecture. Insulin action, diabetogenes, and the cause of type II diabetes. Diabetes 43, 1066-1084 (1994).

4. Roberts, A. C. \& Porter, K. E. Cellular and molecular mechanisms of endothelial dysfunction in diabetes. Diab Vasc Dis Res 10, 472-482 (2013)

5. Chen, H. et al. Evidence that the diabetes gene encodes the leptin receptor: identification of a mutation in the leptin receptor gene in $\mathrm{db} / \mathrm{db}$ mice. Cell $\mathbf{8 4}$, 491-495 (1996)

6. King, A. J. The use of animal models in diabetes research. Br J Pharmacol 166, 877-894 (2012).

7. Yoshida, S. et al. AS1907417, a novel GPR119 agonist, as an insulinotropic and beta-cell preservative agent for the treatment of type 2 diabetes. Biochem Biophys Res Commun 400, 745-751 (2010).

8. Gault, V. A., Kerr, B. D., Harriott, P. \& Flatt, P. R. Administration of an acylated GLP-1 and GIP preparation provides added beneficial glucose-lowering and insulinotropic actions over single incretins in mice with Type 2 diabetes and obesity. Clin Sci (Lond) 121, 107-117 (2011).

9. Kavvoura, F. K. \& Owen, K. R. Maturity onset diabetes of the young: clinical characteristics, diagnosis and management. Pediatr Endocrinol Rev 10, 234-242 (2012).

10. Yamagata, K. et al. Mutations in the hepatocyte nuclear factor-1alpha gene in maturity-onset diabetes of the young (MODY3). Nature 384, 455-458 (1996).

11. Malecki, M. T. \& Mlynarski, W. Monogenic diabetes: implications for therapy of rare types of disease. Diabetes Obes Metab 10, 607-616 (2008).

12. Yang, Q. et al. Hepatocyte nuclear factor-1alpha modulates pancreatic beta-cell growth by regulating the expression of insulin-like growth factor-1 in INS-1 cells. Diabetes 516, 1785-1792 (2002).

13. Takahashi, K. \& Yamanaka, S. Induction of pluripotent stem cells from mouse embryonic and adult fibroblast cultures by defined factors. Cell 126, 663-676 (2006).

14. Takahashi, K. et al. Induction of pluripotent stem cells from adult human fibroblasts by defined factors. Cell 131, 861-872 (2007).

15. Jang, J. et al. Disease-specific induced pluripotent stem cells: a platform for human disease modeling and drug discovery. Exp Mol Med 44, 202-213 (2012).

16. Kudva, Y. C. et al. Transgene-free disease-specific induced pluripotent stem cells from patients with type 1 and type 2 diabetes. Stem Cells Transl Med 1, 451-461 (2012).

17. Teo, A. K. et al. Derivation of human induced pluripotent stem cells from patients with maturity onset diabetes of the young. J Biol Chem 288, 5353-5356 (2013).

18. Hua, H. et al. iPSC-derived $\beta$ cells model diabetes due to glucokinase deficiency. J Clin Invest 123, 3146-3153 (2013).

19. Liu, J. et al. Generation of stable pluripotent stem cells from NOD mouse tail-tip fibroblasts. Diabetes 60, 1393-1398 (2011)

20. Liu, Y. J. et al. Hemangiopoietin, a novel human growth factor for the primitive cells of both hematopoietic and endothelial cell lineages. Blood 103, 4449-4456 (2004).

21. Zambidis, E. T. et al. Expression of angiotensin-converting enzyme (CD143) identifies and regulates primitive hemangioblasts derived from human pluripotent stem cells. Blood 112, 3601-3614 (2008).

22. Grochot-Przeczek, A. et al. Heme oxygenase-1 is required for angiogenic function of bone marrow-derived progenitor cells: role in therapeutic revascularization. Antioxid Redox Signal 20, 1677-1692 (2014).

23. Poels, M. W. J. et al. Enhanced Collagen Type IV Based Differentiation of Embryonic Stem Cells Towards Flk-1 Expressing Vascular Progenitors by the Wnt/ $\beta$-Catenin Synergist QS11. Macromol Symp 309-310, 236-243 (2011).

24. Pagliuca, F. W. et al. Generation of functional human pancreatic $\beta$ cells in vitro. Cell 159, 428-439 (2014)

25. Jeon, K. et al. Differentiation and transplantation of functional pancreatic beta cells generated from induced pluripotent stem cells derived from a type 1 diabetes mouse model. Stem Cells Dev 21, 2642-2655 (2012).

26. Ding, H. \& Triggle, C. R. Endothelial cell dysfunction and the vascular complications associated with type 2 diabetes: assessing the health of the endothelium. Vasc Health Risk Manag 1, 55-71 (2005).

27. Hadi, H. A. \& Suwaidi, J. A. Endothelial dysfunction in diabetes mellitus. Vasc Health Risk Manag 3, 853-876 (2007).

28. Fadini, G. P. et al. Circulating endothelial progenitor cells are reduced in peripheral vascular complications of type 2 diabetes mellitus. J Am Coll Cardiol 45, 1449-1457 (2005).

29. Menegazzo, L., Albiero, M., Avogaro, A. \& Fadini, G. P. Endothelial progenitor cells in diabetes mellitus. Biofactors 38, 194-202 (2012).

30. Ren, J. Leptin and hyperleptinemia - from friend to foe for cardiovascular function. J Endocrinol 181, 1-10 (2004). 
31. Schroeter, M. R. et al. Leptin promotes the mobilization of vascular progenitor cells and neovascularization by NOX2-mediated activation of MMP9. Cardiovasc Res 93, 170-180 (2012).

32. Basile, D. P. \& Yoder, M. C. Circulating and tissue resident endothelial progenitor cells. J Cell Physiol 229, 10-16 (2014).

33. Józkowicz, A. et al. Nitric oxide mediates the mitogenic effects of insulin and vascular endothelial growth factor but not of leptin in endothelial cells. Acta Biochim Pol 46, 703-715 (1999).

34. Park, H. Y. et al. Potential role of leptin in angiogenesis: leptin induces endothelial cell proliferation and expression of matrix metalloproteinases in vivo and in vitro. Exp Mol Med 33, 95-102 (2001).

35. Nakagawa, K. Leptin causes vasodilation in humans. Hypertens Res 25, 161-165 (2002).

36. Matsuda, K. et al. Leptin causes nitric-oxide independent coronary artery vasodilation in humans. Hypertens Res 26, 147-152 (2003).

37. Fagiani, E. \& Christofori, G. Angiopoietins in angiogenesis. Cancer Lett 328, $18-26$ (2013).

38. Józkowicz, A. et al. Heme oxygenase and angiogenic activity of endothelial cells: stimulation by carbon monoxide and inhibition by tin protoporphyrin-IX. Antioxid Redox Signal 5, 155-162 (2003).

39. Dulak, J., Deshane, J., Jozkowicz, A. \& Agarwal, A. Heme oxygenase-1 and carbon monoxide in vascular pathobiology: focus on angiogenesis. Circulation 117, 231-241 (2008).

40. Schiekofer, S., Galasso, G., Sato, K., Kraus, B. J. \& Walsh, K. Impaired revascularization in a mouse model of type 2 diabetes is associated with dysregulation of a complex angiogenic-regulatory network. Arterioscler Thromb Vasc Biol 25, 1603-1609 (2005).

41. Kotlinowski, J. et al. PPAR $\gamma$ activation but not PPAR $\gamma$ haplodeficiency affects proangiogenic potential of endothelial cells and bone marrow-derived progenitors. Cardiovasc Diabetol 13, 150 (2014).

42. Chan, E. M., Ratanasirintrawoot, S. \& Park, I. H. Live cell imaging distinguishes bona fide human iPS cells from partially reprogrammed cells. Nat Biotechnol 27, 1033-1037 (2009).

43. Hrvatin, S. et al. Differentiated human stem cells resemble fetal, not adult, $\beta$ cells. Proc Natl Acad Sci U S A 111, 3038-3043 (2014).

44. Machalinska, A. et al. Long-term neuroprotective effects of NT-4-engineered mesenchymal stem cells injected intravitreally in a mouse model of acute retinal injury. Invest Ophthalmol Vis Sci 54, 8292-8305 (2013).

45. Sommer, C. A. et al. Induced pluripotent stem cell generation using a single lentiviral stem cell cassette. Stem Cells 27, 543-549 (2009).

46. Watanabe, K. et al. A ROCK inhibitor permits survival of dissociated human embryonic stem cells. Nat Biotechnol 25, 681-686 (2007).

47. Castegnaro, M., Massey, R. C. \& Walters, C. L. The collaborative evaluation of a procedure for the determination of $\mathrm{N}$-nitroso compounds as a group. Food Addit Contam 4, 37-43 (1987).

48. Maehr, R. et al. Generation of pluripotent stem cells from patients with type 1 diabetes. Proc Natl Acad Sci U S A 106, 15768-15773 (2009).

49. Schroeder, I. S., Rolletschek, A., Blyszczuk, P., Kania, G. \& Wobus, A. M Differentiation of mouse embryonic stem cells to insulin-producing cells. Nat Protoc 1, 495-507 (2006).
50. Suzuki, J. et al. Antizyme is necessary for conversion of pancreatic tumor cells into glucagon-producing differentiated cells. Endocr Relat Cancer 16, 649-59 (2009).

51. Sommer, C. A. et al. Excision of reprogramming transgenes improves the differentiation potential of iPS cells generated with a single excisable vector. Stem Cells 28, 64-74 (2010).

52. Kang, N. Y., Yun, S. W., Ha, H. H., Park, S. J. \& Chang, Y. T. Embryonic and induced pluripotent stem cell staining and sorting with the live-cell fluorescence imaging probe CDy1. Nat Protoc 6, 1044-1052 (2011).

\section{Acknowledgments}

We would like to thank dr Gustavo Mostoslavsky and dr. Maciej Wiznerowicz for providing hSTEMCCA construct as well as plasmids and cells for production of lentiviral vectors. We also thank Ms. Elzbieta Slizewska and Ms. Ewa Werner for help in conducting teratoma formation assays and Antonina Chmura-Skirlinska for analysis of NO production. This study was supported by the Foundation for Polish Science via VENTURES program (2011-8/8) awarded to J.Stepniewski, by the statutory funds of Collegium Medicum, Jagiellonian University, Krakow, Poland awarded to M. T. Malecki (K/ZDS/002808), by the European Union Framework Program POIG 01.02.00-069/09 and by National Science Center (Maestro program 2012/06/A/NZ1/00004, awarded to J. Dulak). MS was supported by the Polish National Research Foundation "New directions for clinical characteristics of patients with MODY (maturity onset diabetes of the young)" nr ODW-5224/B/P01/2011/ 40. Faculty of Biochemistry, Biophysics and Biotechnology of Jagiellonian University is a partner of the Leading National Research Center (KNOW) supported by the Ministry of Science and Higher Education.

\section{Author contributions}

J.D., A.J., J.S., N.K.T. and M. Malecki designed experiments. J.S., D.O., N.K.T. and M.B. performed experiments. M.S. collected patients and healthy donors. M. Matlok performed skin biopsies, G. Dyduch analyzed the tumors, J.S., A.J. and J.D. analyzed results and wrote the manuscript.

\section{Additional information}

Competing financial interests: The authors declare no competing financial interests.

How to cite this article: Stepniewski, J. et al. Induced pluripotent stem cells as a model for diabetes investigation. Sci. Rep. 5, 8597; DOI:10.1038/srep08597 (2015).

This work is licensed under a Creative Commons Attribution 4.0 International License. The images or other third party material in this article are included in the article's Creative Commons license, unless indicated otherwise in the credit line; if the material is not included under the Creative Commons license, users will need to obtain permission from the license holder in order to reproduce the material. To view a copy of this license, visit http://creativecommons.org/licenses/by/4.0/ 